\title{
Club Enlargement: Early Versus Late Admittance ${ }^{1}$
}

\author{
M ike B urkart \\ Stockholm School of Economics \\ C.E.P.R. \\ K laus Wallner \\ Stockholm School of Economics
klaus.wallner@hhs.se \\ Stockholm School of Economics
klaus.wallner@hhs.se \\ mike.burkart@hhs.se

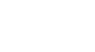

September 13, 1999

PRELIMINARY AND INCOMPLETE

\begin{abstract}
${ }^{1}$ Send correspondence to K laus Wallner, SITE, Stockholm School of Economics, PO Box 6501, S11383 Stockholm, ph: ++46-8-736 9684, fax: ++46-8-316 422. We would like to thank Tore Ellingson, Denis Gromb, B engt Holmström, A lexander M atros, Paul Segerstrom, J örgen W eibull, K senia Yudaeva, and workshop participants at SITE and the CEPR transition workshop in Budapest 1999 for valuable comments and discussion. Financial support from J an W allander Stiftelse (Burkart) and Utrikespolitiska Institutet (Wallner) is gratefully acknowledged. All remaining errors are our own.
\end{abstract}




\begin{abstract}
A bstract
W ithin an incomplete contract framework, we analyze the enlargement strategy of a club facing applicants that dixer in wealth and reform status. W hile an applicant bene..ts from entry, the club only gains if the entrant makes an adjustment investment. The club has a choice between early admittance, using its limited internal enforcement powers to ensure reform, and late admittance conditional on prior reform. Wealthy candidates enter early as the club can charge a higher entrance fee for undiscounted membership bene..ts. For poor applicants, the club applies a reversed admittance order: A less advanced applicant is admitted early to reform as member, while a more advanced enters late after it has reformed. Moreover, the admittance rents increase in the ratio of reform distance to wealth. The viability of the late admittance strategy depends on the club's commitment ability. If the club can credibly commit to a stage..nancing schedule, it can induce applicants to reform without overfunding. In the repeated game, the threat of denying additional funding is not credible, and more overfunding is required for reform.
\end{abstract}




\section{Introduction}

Much economic activity evolves around clubs (T iebout (1956), Buchanan (1965)). O wing to its public choice origins, the club literature has primarily analyzed the level of 'club good' provision and the equilibrium club size (Sandler and T schirhart (1980) and Cornes and Sandler (1996)). To mitigate free riding problems, most clubs are endowed with a monopoly over the club entrance decision. This paper studies the strategic use of this exclusive right in the admittance of new members.

M ore speci..cally, we analyze a club's decision to admit an applicant whose type is characterized by its wealth and a reform requirement. While the entrant bene.ts from membership, the club only gains if the entrant reforms. Reform investments are not contractible. The club has a choice between early, late and no oxer. This choice matters for an applicant's incentives and ability to reform. With early admittance, the club can apply its imperfect internal enforcement tools to force the entrant to reform. Under a late oxer, admittance is conditional on prior reforms and the future membership bene..ts provide incentives to adopt to the club's standard.

Wealthy applicants are willing to pay more for joining the club early rather than late. Thus, beyond a certain wealth level, the club makes only early oxers. Poor applicants are oxered a reversed admittance order: Advanced types enter late only after having reformed, while less advanced types enter early and reform as new members. The prospect of future membership bene..ts provides incentives for applicants to reform rather than consume. By giving the applicant more money, the club raises the incentive to reform with a late oxer. The additional funds generate a higher marginal utility if the applicant reforms (when consumption is lower) than otherwise. The overfunding needed to incduce reform increases with the reform distance. As a result, the use of leverage from late conditional admittance is a more costed cient strategy only for advanced types. For less advanced types, the early oxer is cheaper because the club can ensure through its imperfect internal control that at least a portion of the reform funds is used for reform. Thus, both oxers concede rents to the applicants that increase in the reform distance.

The power of using future membership bene..ts as incentive mechanism, and hence, the viability of the late admittance strategy depends on the club's commitment ability. If the club can commit not to renegotiate a stage...nancing schedule, it can split the reform requirement into small steps and reduce the late oxer transfer to the pure reform ..nance. Opportunistic 
behavior in the repeated enlargement game makes an incentive compatible late oxer more costly, and the set of late oxer types shrinks.

A topical application for our framework is the Eastern Enlargement of the EU. Membership applicants from Central and Eastern Europe (CEE) are severely ..nancially constrained, and attainment of EU standards is often not their optimal development strategy because EU standards suit a rich group of highly developed countries. The twin roles of ..nancier and enlargement monopolist give the EU strong in $¥$ uence over the reform agenda of applicants. Unlike B erglöf and Roland (1998), we allow for ..nancing of reforms ahead of entry. We assume that complete contracts with a speci..ed reform level are not possible because either reform is non-veri..able or there is no enforcement institution with authority over sovereign countries.

This paper is closely related to the literature on the coexistence of direct and intermediated lending. In moral hazard models of direct and indirect lending (e.g., Diamond 1991, Holmström and Tirole 1997), there are typically three regimes. Firms with su cient wealth can issue direct debt. Firms with fewer own assets engage in asset substitution, unless they are monitored. Hence, they can only borrow from banks. Finally, undercapitalized ..rms cannot raise outside ..nance. These three outcomes correspond to the late, early, and no admittance oxer in our framework where the reform distance can be interpreted as a measure of the moral hazard problem. Using future membership bene.ts as an incentive mechanism resembles the use of a liquidation threat or denial of future access to funding as instruments to discipline borrowers in a setting without collaterals or suф cient pledgeable returns (e.g., B olton and Scharfstein 1990, Hart and Moore 1994, Gromb 1994).

The paper is organized as follows. We describe the model in Section 2. Section 3 characterizes the enlargement strategy of the club in the one-shot game. In Section 4, we restrict attention to applicants with zero wealth, and allow for several sequential transfers. We analyze opportunistic behavior and the role of commitment power with a late conditional oxer. We conclude in Section 5. Mathematical proofs are in the A ppendix.

\section{Model}

\subsection{Framework}

A club composed of homogeneous members that act as a single player faces an applicant for membership. The applicant's type is de..ned by its wealth w, 0 and its reform requirement $d$; where $d^{\prime} x^{C}$ i $x^{0}>0$ is the distance between its initial position $x^{0} 2^{i} 0 ; x^{C}$ and the club 
standard $\mathrm{x}^{\mathrm{C}}$ along some reform dimension $\mathrm{x}$. W hile $\mathrm{x}$ is observable, it is not veri..able.

Reform is modeled as a costly adjustment of the applicant's initial position towards the club standard. Our focus is on conformity requirements rather than reforms that raise the applicant's welfare directly.

A ssumption 1 (Reform) Investment in $\mathrm{x}$ yields no direct return to the applicant, but bene..ts the incumbent members of the enlarged club.

By investing $F$ in reform the applicant moves from $x^{0}$ to $x=x^{0}+F{ }^{1}$ Feasibility requires that F . w+s; where S $2 \mathrm{R}$ is the ..nancial transfer with an admittance oxer. We assume that the club has ..nancial slack. If an applicant has insuф cient funds to meet the club standard, the club has to provide the necessary funds. ${ }^{2}$ A positive transfer is a subsidy from the club to the applicant, while a negative one is an entrance fee the club charges for membership.

Instead of investing into reforms, the applicant may use its resources ( $w+S$ i $F$ ) for consumption. The utility function $u_{2} R_{+} ! R_{+}$is twice continuously digerentiable with $u(0)=0 ; u^{0}>0$ and $u^{\boxplus}<0$ :

Besides rejecting an applicant, the club has two enlargement strategies. The club can oxer late admittance conditional on prior reform investment. Alternatively, it can oxer early admittance, where any investment in meeting the club's standard is undertaken after the applicant has joined. By joining the club, the entrant becomes subject to club rules and institutions.

A ssumption 2 (Internal Control) Under an early admittance oxer, the club can enforce the use for reform of a fraction ${ }^{\circ} 2(0 ; 1)$ of an entrant's post-entry wealth, while it has no enforcement power over non-members.

Even if the club provides reform funds, the applicant retains full discretion over the use of its entire resources $(w+s)$ under a late oxer. In contrast, a newly admitted member controls only a fraction $\left(1 \mathrm{i}^{\circ}\right)$, where ${ }^{\circ}$ rełects the strength of internal enforcement powers of the club. We assume that the club uses its enforcement powers to maximize the reform status of the new member even if full reform is not feasible.

\footnotetext{
${ }^{1}$ We assume that an investment in $\mathrm{x}$ is inconsequential for the value of the applicant's outside option. Rather than analyzing a hold-up problem arising from investment ideosyncracy, we focus in the following on the use of leverage from a late conditional entry oxer for setting reform incentives.

${ }^{2}$ T he applicant has no projects that generate returns it could pledge to outsiders. Hence, the club is the sole potential lender. Note, however, that outside lenders could provide an incentive compatible transfer s. (Independent of the source of $\mathrm{s}$; the club gladly accepts new members whose reform investments it did not have to fund.) W hile s does not have to be provided by the club, outsiders do not get the enlargement gain ${ }^{R}$ and hence, have no incentives to provide reform ..nance.
} 
The club, i.e., its current members realizes an enlargement gain ${ }^{R}$ from a fully adjusted new member, while it gets ${ }^{U}<0<\left.\right|^{R}$ if the new member fails to meet the standard. In order to focus on the link between admittance and reform, we exclude that the club can pro..tably sell membership irrespective of reform.

A ssumption 3 (Unreformed Entry) $\}^{U}+\mathrm{u}^{\mathrm{i}}\left({ }^{1 / 4}<0\right.$ :

The expression $u^{i}{ }^{1}(1 / 4)$ is the most the club can extract from an applicant when admittance does not lead to reform. Hence, for $i^{U}+u^{i}{ }^{1}\left({ }^{1} / 4<0\right.$ the club strictly prefers no oxer to a nonreform implementing oxer (see Lemma 15). Henceforth, unless explicitly stated, we abstract from oxers that do not induce reform. Membership yields a bene..t 1/4to the applicant regardless of $\mathrm{x}$; i.e., its degree of conformity with the club standard. While all parameters and variables are observable, only the receipts of payments and the entry into the club are veri..able. Hence, contracts on payoxs $\left(1 / 4 a n d i^{R}\right)$ or reform $(x)$ are not enforceable and a conditional late entry oxer must instead be self-enforcing. ${ }^{3}$ Furthermore, the applicant's payox function is additively separable in the membership bene.t $1 / 4$ and the utility $u(\phi$ from consumption.

All decisions in the game are taken in a single period, referring to reform time rather than real time. At date 0 , the club makes an admittance oxer to the applicant. More precisely, the club chooses the triple $(x ; s ; j)$ where $x \cdot x^{C}$ is the reform requirement, s $2 R$ is the ..nancial transfer, and $\mathrm{j}=\mathrm{L} ; \mathrm{E} ; \mathrm{N}$ is the timing of enlargement (late, early, and no oxer). Then the applicant either accepts or rejects the oxer. If no entry was oxered, or if the applicant rejects an oxer, the game ends and both players get the reservation payoxs normalized to zero. U pon acceptance, the amount $\mathrm{s}$ is transacted and the applicant decides on the levels of reform investment and consumption. At date $1, x$ realizes and the late conditional contract is executed. Figure 1 shows the timing of moves. There is a common discount factor $\pm<1$. Hence, the date 0 value of the late enlargement bene.ts is \pm and $\# k$; $k=U ; R$ : For simplicity, the dixerence to the club between late entry and initially unreformed early entry with subsequent reform is negligible. Hence, the payox to the club from early entry is $\sharp^{R}$ if the new member reaches $\mathrm{x}^{\mathrm{C}}$ by date 1 ; but ${ }^{\mathrm{U}}{ }^{\mathrm{C}}$ otherwise.

\footnotetext{
${ }^{3}$ If $1 / 4$ were veri..able, the club could contractually impose a penalty (withholding ${ }^{1 / 4}$ on elarly entrants failing to reform. As a result, reform could be implemented at a cost equal to the actual reform requirement, and early oxers would weakly dominate late ones.
} 


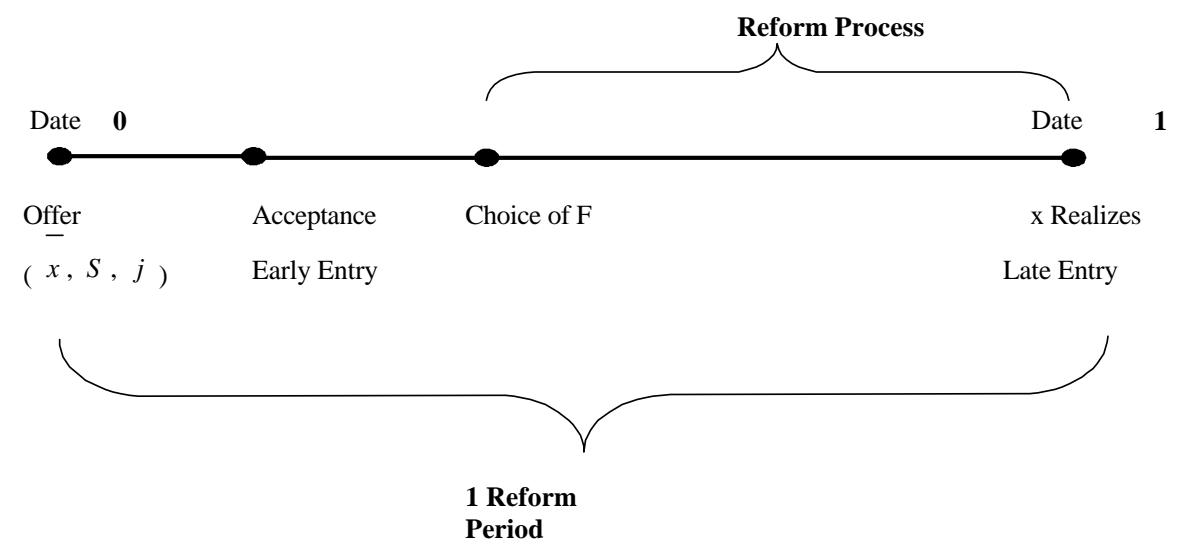

Figure 1: Timing

\subsection{Discussion}

A ssumption 1 is motivated by the observation that many club standards are arbitrary or historically determined rather than inherently optimal, except that members adhere to them. For instance, when the Channel Tunnel project provided for a railway connection between the UK and continental Europe, England faced the pure adjustment cost of altering its railway track width. Our focus is on such conformity requirements rather than reforms that raise the applicant's welfare directly. That is, investing in the club standard constitutes a deviation from the applicant's optimal stand-alone resource allocation or development path.

At the point of joining, entrants typically submit to explicit and implicit club rules, surrendering some of their discretionary powers. Enforcement institutions may be formal, such as the European Court of J ustice, or the arbitration mechanism of the WT O. Informal disciplining tools include the threat of expulsion, peer pressure, and discriminatory treatment in other aspects of club membership.

The club's enlargement payoxs $!^{U}<0<\left.\right|^{R}$ are meant to refect in a simple way that heterogeneity introduces frictions and inhibits decision making, and hence, is costly to the club. In the EU example, enlarging the membership list from 15 to over 20 requires reform of the unanimity decision culture that has evolved over the initial decades of the EC under smaller membership numbers. Heterogeneity in income, objectives and institutions makes collective action more dic cult to coordinate. Furthermore, the more diverging standards are, the smaller the gains from trade among the club members.

The entrant's membership bene.ts $1 / 4$ are assumed to be independent of his reform status 
and predetermined. Making $1 / 4$ sensitive to reform investments would move us away from the public good notion of the value of a club. Obviously, if bene..ts are sensitive to reform, the moral hazard problem is mitigated. The bene.ts $1 / 4$ being a variable over which the club has no discretion captures the notion that they are predetermined by applying the current club rules to the newly admitted member. For example, the EU faces high (possibly prohibitive) costs of altering the sections of the acquis communautaire that detail the agricultural and regional support funds for which new members qualify. In addition, we assume that club rules prohibit exclusion from the club after entry, and that the rules can only be changed by a unanimous vote of all members. Hence, the club cannot use the threat of exclusion in the early entry case to induce the entrant not to consume the resources under its discretion.

There are three possible interpretations for the additively separable payox function of the applicant. First, the applicant is a single agent and the private bene.t 1/4is non-monetary and non-transferable. Second, the applicant consists of a large group of individuals and the membership bene..ts accrue to a dixerent set than the utility from consumption. Third, with veri..able bene..ts, club rules may exclude the withholding of membership bene.ts in response to insuf..cient reform. For instance, the $\mathrm{EU}$ could not coerce Greece into implementing environmental safety measures with the threat of withholding Structural Funds or CA P payments. (Similarly, it is generally not possible for a state to reduce a convict's pension claim as punishment.)

\section{The Optimal A dmittance Strategy}

We solve for the optimal admittance strategy by backwards induction. First, we derive the minimum necessary transfer s to implement reform, given that the applicant has accepted an early or late oxer. Second, we solve for the minimum necessary transfer such that an applicant accepts an early or a conditional late oxer, given that full reform is subsequently implemented. Finally, we compare the cost of inducing any applicant type to accept an early or late oxer and to reform. Bearing in mind that the club can also refrain from making an oxer, the optimal admittance strategy obtains as a function of the applicant type.

The club maximizes $\#^{R}$ i $s$ by choosing a reform threshold $x$, a transfer $s 2 R$, and the type of oxer $\mathrm{j}=\mathrm{fE} ; \mathrm{L} ; \mathrm{Ng}$, subject to the applicant's optimal response. ${ }^{4}$ At date $1, x$ realizes as a function of the reform investment. The decisions left to the club depend on whether it has made an early or late admittance oxer at date 0 : In the case of an early oxer, the applicant has

\footnotetext{
${ }^{4}$ In fact, the club's payou range includes $U$ i s. By A ssumption 3, unreformed entry is strictly dominated, and we restrict the analysis here to reformed entry. The case of unreformed entry is addressed in Appendix $H$.
} 
al ready been admitted and $\#^{R}$ materializes mechanically. For $x=x^{C}$; the date 0 value of the enlargement is $\#^{R}$ i $S$ and $U_{i}$ s otherwise. The entrant gets $1 / 4+U(w+S$ i $F)$ independent of $x$. In case of a late oxer, the club has to take the ..nal admittance decision. The date 0 value of the enlargement payox to the club is $\#^{R}$ i $s$ if $x=x^{C}$ and $\#^{U} i s$ otherwise. If the club refuses admittance, its payox is i s. Because the players cannot contract upon $\mathrm{x}$; the admittance oxer needs to be self-enforcing, i.e., subgame perfect. Hence, the club admits the applicant if $\mathrm{x}=\mathrm{x}^{\mathrm{C}}$ and rejects it otherwise. For the time being, we assume that the club has set $\mathrm{X}=\mathrm{x}^{\mathrm{C}}$ and show later that it does indeed do so. Given this admittance rule, the applicant gets a payo with a date 0 value of $\underline{x} / 4+u(w+S$ i $F)$ if $x, x$, and $u(w+S$ i $F)$ otherwise.

Upon acceptance of an oxer, $\mathrm{s}$ is transferred, and the reform investment decision is taken. Let $d^{\prime}$ ' $\mathbf{x}_{\mathbf{~}} \mathbf{x}^{0^{\phi}}$ denote the distance between the applicant's initial position and the club's reform requirement. The club gains from enlargement if the applicant or newly admitted member fully reforms, i.e., if $x=x=x^{C}$.

Lemma 1 (Reform Implementation) Under both early and late admittance, full reform can be implemented for any type $(d ; w)$ :

(i) In an early admittance oxer, the minimum necessary transfer is

$$
s^{E 0}=\frac{d}{0} i \quad w:
$$

(ii) In a late admittance oxer, the mimimum necessary transfer is

$$
s^{L 0}=\begin{aligned}
& 1 / 2 \\
& d_{i} w \text { if } d<\hat{d ;} \\
& s(d ; w) \text { otherwise, }
\end{aligned}
$$

where $\hat{d}=u^{i}{ }^{1}( \pm / 4$ and $\hat{s}(d ; w)$ solves $\pm / 4+u(w+s ; d)=u(w+s)$ : Furthermore, $\hat{d}$ is increasing and $\mathbf{s}$ decreasing in \pm

In the case of early admittance, the entrant already enjoys the membership bene.ts and has no incentive to reform. Instead, it spends all its discretionary resources $\left(1 i^{\circ}\right)(w+s)$ on consumption. Depending exclusively on the club's limited internal enforcement, full reform is feasible only if the entrant's total resources after entry are no less than $\frac{d}{o}$. Hence, the club has to set $s$ such that ${ }^{\circ}(w+s)$, $d$. While the club can induce reform for any early entrant, the cost $\frac{d}{o} \mathrm{i}$ w becomes prohibitive for su $\phi$ ciently unreformed types. The borderline above which the club prefers no enlargement to the early oxer is given by $d^{N E}={ }^{\circ}{ }^{i}{ }^{R}+w^{\Phi}$ :

In the case of late admittance, investment in $\mathrm{F}$ is of value to the applicant only if it leads to entry, but comes at the opportunity cost of forgone consumption. Hence, the applicant either 
does not reform $(F=0)$ or invests exactly the amount needed to meet the entry condition $(F=d)$. For full reform to be feasible, the club must leave the applicant at least $s=d_{i} \mathbf{w}$. Having the necessary funds at their disposal, only the most advanced applicant types $(d \cdot \hat{d})$ reform fully. For all other types $(d>\widehat{d})$, the utility from diverting $d_{i} w$ exceeds the future membership bene.ts. Nonetheless, the club can induce these types to reform by giving them a larger amount. Such overfunding renders reform incentive compatible, because the marginal utility of consuming $w+s i d$ is larger when $d$ is invested in reforms than when the entire $w+s$ is used for consumption. The minimum late oxer transfer that provides reform incentives is $\mathrm{S}$. This transfer increases in $d$ but decreases in $\pm^{5} \mathrm{~A}$ larger $\mathrm{d}$ raises the opportunity cost of reform, while a larger \pm raises the bene.t of reform. Finally, for every wealth level, there is a critical reform distance $d$ above which the late oxer ceases to be pro..table for the club. The borderline is given by $\#^{R}=\hat{S}$, which de. nes an increasing and concave curve $d^{N L}=w+\#^{R}$ i ui ${ }^{f} u^{i} \#^{R}+w^{\phi} i \stackrel{\alpha}{\alpha} \pm_{4}^{\alpha}$ :

The club's optimal admittance strategy does not follow directly from the lowest implementation cost of reform. In addition, an applicant must also accept an early or a late oxer. The minimum necessary transfer that is both accepted and implements reform obtains from comparing implementation and individual rationality constraints in each case.

Lemma 2 (Acceptance Early) An applicant accepts a reform-implementing early oxer with a minimum transfer

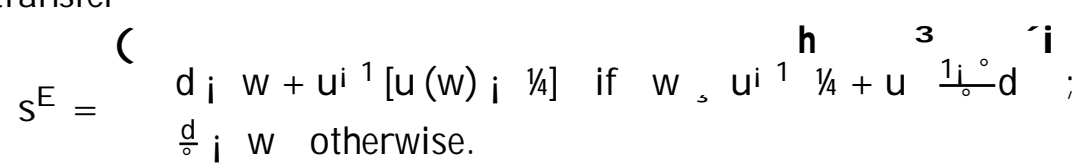

F igure 2 shows how the applicant types are separated according to the binding constraint. In Region I; applicants are poor relative to their distance to the club standard. Therefore, the club has to leave the applicant suф cient funds. That is, the binding FC-E determines $\mathrm{s}^{\mathrm{E}}$ : A pplicants in Region II are relatively wealthy, and the entrance fee is constrained by their outside option of not joining, $\mathrm{U}(\mathrm{w})$ : All types for which the FC-E and the IR-E simultaneously bind constitute the curve ${ }^{i} I^{E}{ }^{E} F C^{E}{ }^{\Phi}$; separating Regions I and II. Finally, for any given $\mathrm{W}$; types from Region I require a larger $s$ than those from $1 \mathrm{I}:{ }^{6}$

\footnotetext{
${ }^{5}$ Total dixerentiation of the late oxer transfer $s=d_{i} w+u^{i}\left[u(w+s) i \pm^{1} / 4\right.$ yields

$$
\frac{d s}{d \pm}=i \frac{1 / 4}{u^{0}(w+s i d) i u^{0}(w+s)}<0 \text { and } \frac{d s}{d d}=\frac{u^{0}(w+s i d)}{u^{0}(w+s i d) i u^{0}(w+s)}>0 \text { : }
$$

by concavity of $u$. In general, the curvature of $s^{L}$ in $d$ is ambiguous. (We discuss this issue in A ppendix I.) ${ }^{6} \mathrm{~T}$ he IR -E requires $1 / 4+\mathrm{u} \frac{1_{i}^{\circ}}{\circ} d, u(w)$; where $\frac{1_{i}^{\circ}}{\circ} d$ is the minimum retained after reforming. Manipulation
} 


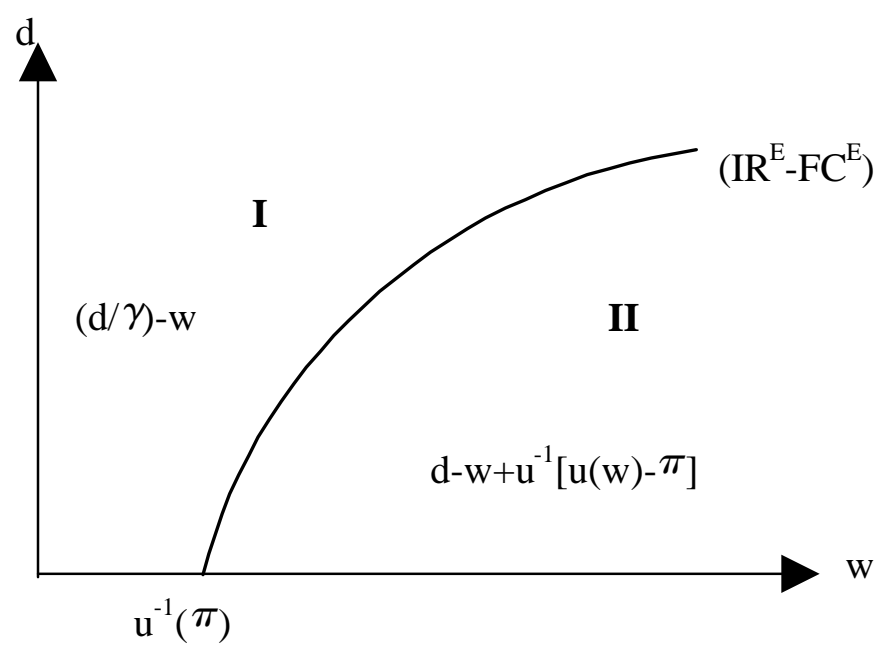

Figure 2: Acceptance Of An Early Oxer

Lemma 3 (Acceptance Late) An applicant accepts a reform-implementing late oxer with a minimum transfer

$$
\begin{aligned}
& 8 \text { s if } d>u^{i}{ }^{1}\left( \pm / 4 \text { and } d>w_{i} u^{i}{ }^{1}[u(w) i t / 4\right.
\end{aligned}
$$

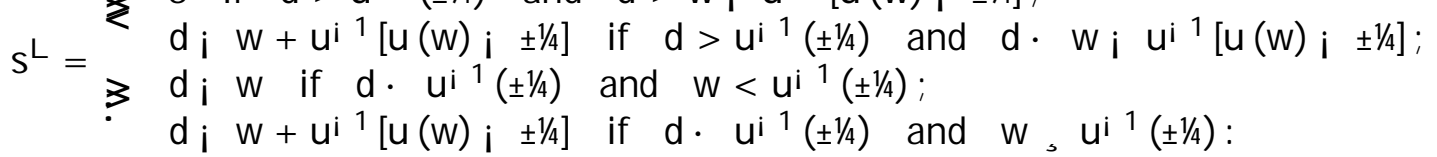

Figure 3 illustrates the binding constraint and consequent transfers for each applicant type. Region I contains applicant types that are relatively poor and have a large reform requirement. For those types, the incentive constraint IC-L binds. The types in R egions II and IV are rich relative to their reform distance, and the minimum accepted transfer is determined by their outside option $u(w)$ : That is, the individual rationality constraint IR-L binds. The dividing line between R egions I and II ; ${ }^{i} I R^{L} ; I C^{L}{ }^{\$}$ is given by the points where the IC $L$ and the IR $-\mathrm{L}$ simultaneously bind. This implies that the transfer is zero on this curve. Applicants in Region III are relatively poor, and the membership bene.t outweighs the utility from consumption. Subsidized types $(d>w)$ do not divert any resources, while types with $d<w$ are willing to pay an entrance fee. Thus, the minimum accepted transfer is determined by the feasibility yields $\frac{d}{\circ} i w, d i w+u^{i}\left[u(w) ; \frac{1}{4}\right.$ : 


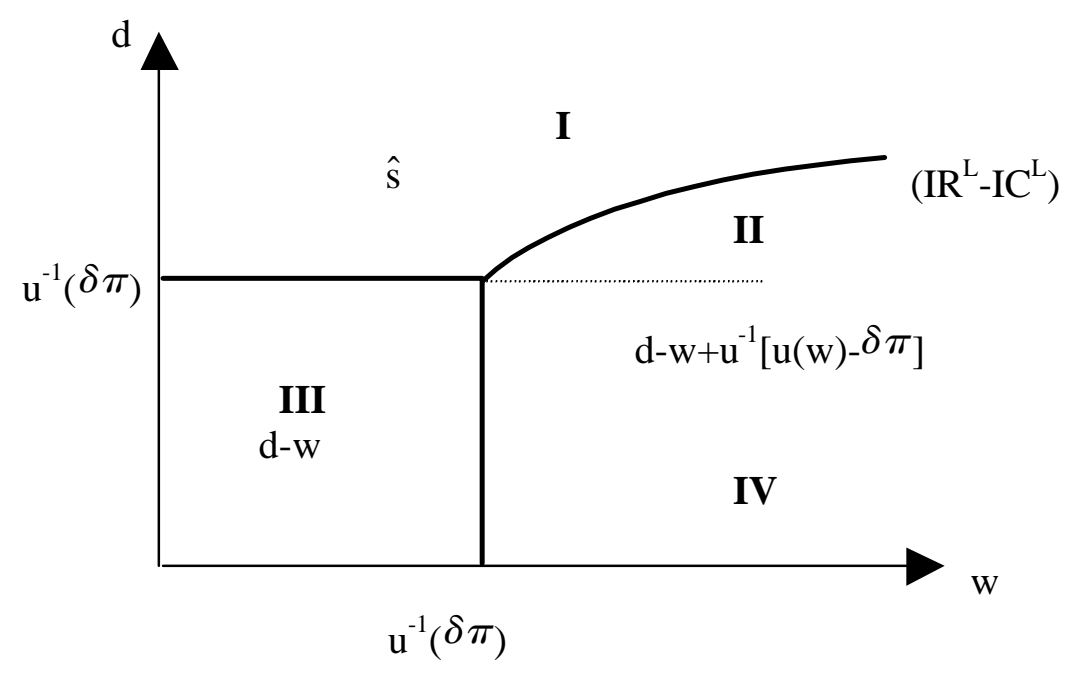

Figure 3: Acceptance Of A Late O xer

constraint FC-L. For any given w; types from R egion I require the largest $\mathrm{s}^{7}$

In addition to the transfer $\mathrm{s}$ and the timing of admittance, an oxer made in the beginning of the period speci..es a threshold $\mathrm{x}$. Setting $\mathrm{x}=\mathrm{x}^{\mathrm{C}}$ is immediate. In a late oxer, the club will admit an applicant at date 1 only if $x=x^{C}$. Hence, a choice $x<x^{C}$ is not time consistent and will simply be ignored by the club at the time of the ..nal admission decision. In an accepted early oxer, $F=d \cdot{ }^{\circ}(w+s)$ by Lemma 2 . That is, the reform investment comes from the club controlled fraction of $w+s$ and the choice of $x$ is inconsequential. Thus, in either oxer it is a weakly dominant strategy for the club to set $x=x^{C}$. While this threshold is implicitly understood by a rational applicant, we assume nonetheless that the club formally announces it.

The above analysis allows us to classify the applicant types into recipients of early, late, and no oxer. To obtain an unambiguous classi..cation, we make a further assumption.

Assumption 4 i) $\pm / 4<u^{i} \Psi_{R}{ }_{i} u^{f}\left(1 ;{ }^{\circ}\right)^{i}{ }_{\#}{ }^{\phi \alpha}$;

ii) $\frac{u^{0}(x)}{u^{0}\left[\left(1_{i}{ }^{\circ}\right) x\right]}>1 i^{\circ} ; 8 x, 0$ :

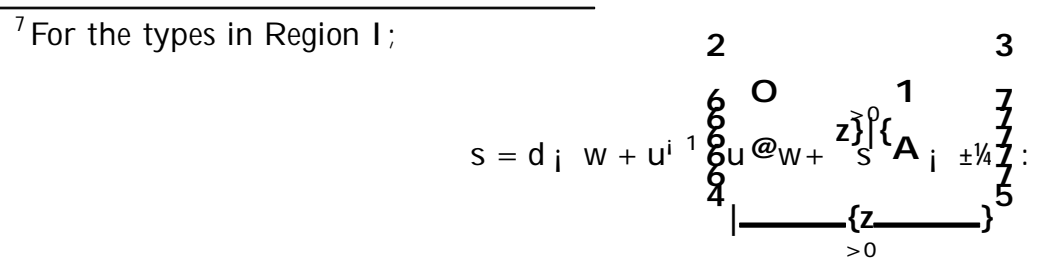

For a given $w$; this is greater than $d_{i} w+u^{i}\left[u(w) ; \pm^{1} / 4\right.$; the transfer for types from Regions II and I V: For types from Region I; $u(w+s) i \pm / 4>0$ implies that the transfer to types in III ( $\left.d_{i} w\right)$ is also less. 


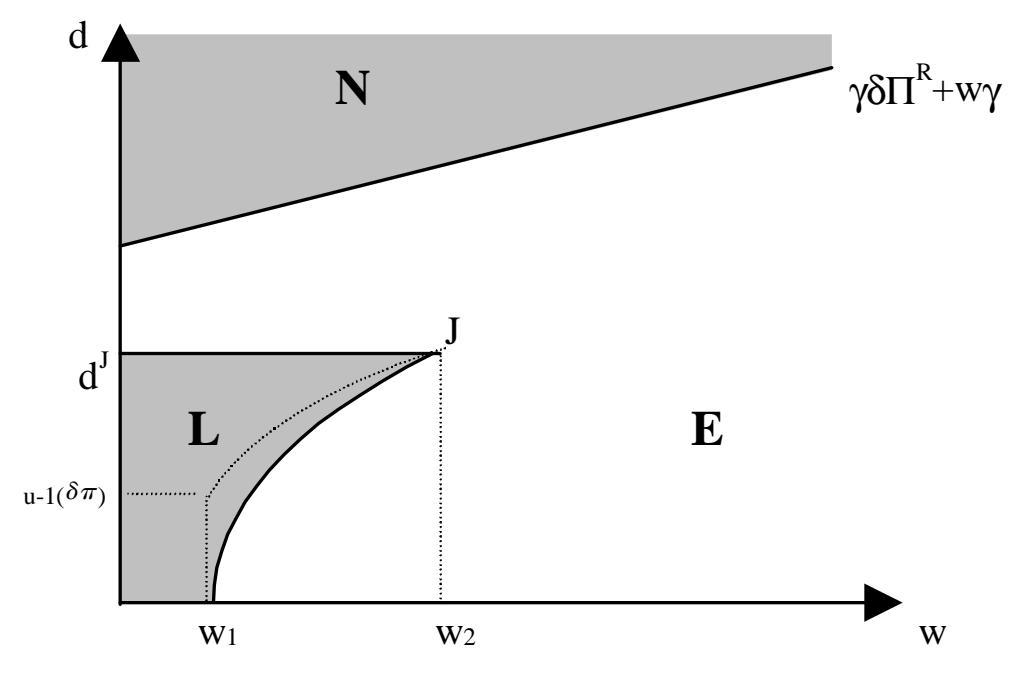

Figure 4: The Optimal Oxer

Part (i) of Assumption 4 ensures that the least pro..table type to get an admittance oxer receives an early one. Part (ii) implies that the set of types for which late is the preferred oxer is connected. ${ }^{8}$ After presenting our results, we discuss the robustness with respect to this assumption. De.ne $w_{1}{ }^{\prime} u^{i}{ }^{1}\left( \pm / A\right.$ and $w_{2}: \pm / 4+u\left[\left(1 ;{ }^{\circ}\right) w\right]=u(w)$ :

Proposition 1 Only types with $w>\frac{d}{o} i \#^{R}$ receive an admittance oxer. Among these types, (i) for $d \cdot w_{1}$; the club follows a 'reversed' admittance order;

(ii) for $w_{1}<w \cdot w_{2}$; the club oxers early entry to the most advanced types, and follows a reversed admittance order otherwise;

(iii) for $w>w_{2}$; the club oxers only early entry.

Figure 4 illustrates the Proposition. On the one hand, entering early rather than late is of value due to discounting. For rich applicants, the marginal utility of wealth is suф ciently low that they are willing to pay a higher price to gain entry early. For rich types, this discount exect dominates. On the other hand, poor types receive reform funding from the club. They have a high marginal utility of wealth and hence, a strong temptation to consume the funds.

\footnotetext{
${ }^{8}$ For example, $u\left(\phi={ }^{p}\right.$ - satis..es Part (ii):

$$
\frac{u^{0}(x)}{u^{0}\left[\left(1 i^{\circ}\right) x\right]}=\frac{\frac{1}{2} x^{\frac{j}{1}}}{\frac{1}{2}\left[\left(1 i^{\circ}\right) x\right]^{\frac{j}{2}}}=\left(1 i^{\circ}\right)^{\frac{1}{2}}>\left(1 i^{\circ}\right):
$$

Logarithmic utility $u\left(\phi=\log \left(\phi\right.\right.$ also satis..es the condition $\frac{u^{0}(x)}{u^{0}\left[\left(1 i^{\circ}\right) x\right]}=\frac{\frac{1}{x}}{\frac{\left(1 i_{i} \circ\right.}{x}}=\frac{1}{1_{i}{ }^{\circ}}>1_{i} \quad$ : $:$ The negative exponential function $u\left(\phi=i e^{i \times}\right.$ does not satisfy Part (ii).
} 
A $n$ incentive compatible late oxer is then more expensive for the club than using its imperfect internal enforcement technology to get reforms implemented. For an intermediate range of wealth relative to reform distance, the cheapest way to induce the applicant to reform is the use of leverage from conditioning entry on prior full reform. In this range, where both $d$ and $\mathrm{w}$ are not too large, neither the wealth exect nor the overfunding exect are suф ciently strong to dominate the leverage exect.

For any given wealth level, types with too large reform distance do not receive an admittance oxer. From a social el ciency perspective, too few types receive oxers. The socially et cient cut-ox rule for the early oxer is $1 / 4+\#^{R}$ i $d=0$, while the club applies $\sharp^{R}$ i $s=0$; where $\mathrm{s}, \mathrm{d}$.

Our notion of reversed order of admission refers to 'reform time' (not calendar time). M ore advanced types, i.e., low d values, are admitted after they have reformed, while less advanced enter prior to reforming. Thus, the enlargement strategy applies "double standards". Unlike more backward candidates, stronger candidates are asked to prove their willingness to conform with the club standard. ${ }^{9}$

Corollary 1 Among the entrants, wealthy types pay an entrance fee in addition to the full reform cost, intermediate types pay part of their reform cost, while poor types receive a rent in addition to their reform cost.

Corollary 1 is illustrated in Figure 5. In Region I, applicants are so poor relative to their reform distance that the club must provide more than the pure reform ..nance; under the late oxer, such overfunding is necessary to meet the incentive constraint, while under the early oxer the club is unable to control all of the new member's reform funds. In Region II; the club and the applicant share the reform costs, while in Region III the applicants are so wealthy and pay not only the full reform cost but in addition an entrance fee. The rent that the least advanced types earn under both early and late oxers (from imperfect internal control over reform funds and from the reform incentive scheme, respectively) rise in the reform distance $d$, making reformed entry eventually prohibitively expensive for the club. Thus, the transfer decreases in the ratio of wealth to reform distance.

\footnotetext{
${ }^{9}$ Our reversed admittance order appears to contradict the common intuition that a club should pick the most advanced applicants for the nearest enlargement. The contradiction resolves if one considers a whole reform period an 'enlargement occasion'. The club then picks indeed the most advanced applicants for the occasion, but over the reform period applies the reversed admittance order.
} 


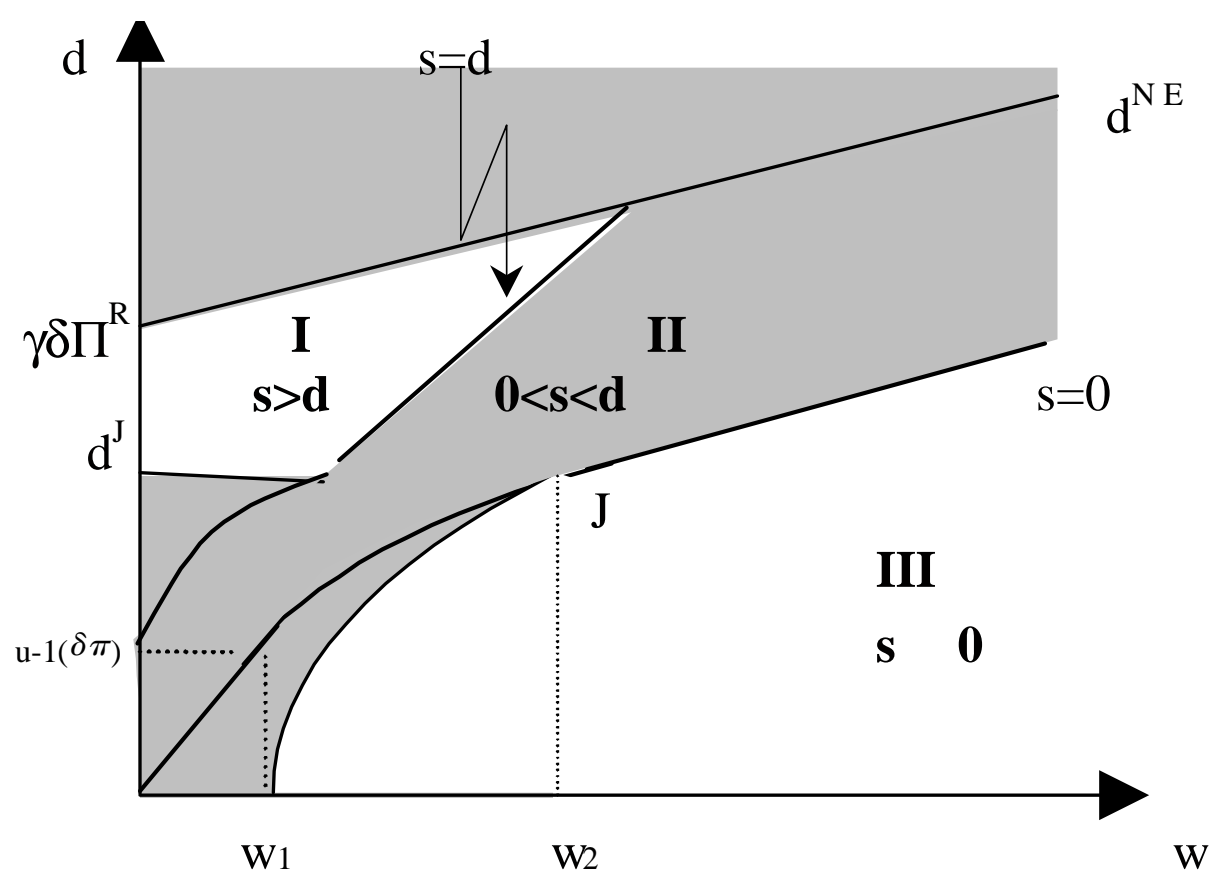

Figure 5: Transfer Payments With The Optimal Oxer

Corollary 2 (i) An increase in ${ }^{\circ}$ enlarges the set of early oxer canditates, and weakly reduces the transfer to all candidates that previously received an oxer.

(ii) An increase in \pm or $1 / 4$ enlarges the set of late oxer candidates, and weakly decreases the transfer to all candidates. In addition, an increase in \pm also strictly enlarges the set of types receiving an oxer.

Stronger internal enforcement ( $a n$ increase in ${ }^{\circ}$ ) makes the early oxer cheaper for the club and turns some previous recipients of late or no oxers into early oxer types. The transfer $\mathrm{s}^{\mathrm{E}}$ falls in those regions where the F C-E is the binding constraint; for wealthy applicants, the FC-E is slack and the IR -E binds, and hence, their entrance fee is unchanged. A rise in the discount factor makes late entry worth more and hence, increases reform incentives. Furthermore, it relaxes the IR-L. A ccordingly, the club substitutes late for early oxers for some candidates. It also shifts $\mathrm{d}^{\mathrm{NE}}$ upwards, and hence, early oxers are made to some former no-oxer types. A larger $1 / 4$ raises the relative attractiveness of the late oxer, because it relaxes the IC $L$ while the FC-E is unaxected. Although it also relaxes the IR-E, the boundaries between early and late oxer lie strictly in the set of types where the FC-E determines $S^{E}$. Hence, while a larger $1 / 4$ lowers S where the IR-E binds, it does not change the type of oxer. 
Proposition 1 crucially depends on Assumption 4. While the discounting exect underlying the assignment of early oxers to wealthy types only requires concavity, the reversed admittance result for poorer types depends on the degree of curvature of $u$. More precisely, the late oxer transfer $\mathrm{S}^{\mathrm{L}}$ for candidates $\mathrm{d}<\mathrm{ui}^{1}( \pm \mathrm{A} / \mathrm{A}$ is determined by the $\mathrm{FC}$ - $\mathrm{L}$ constraint and hence independent of $u$ : A bove the horizontal line $d$, however, early oxers become cheaper beyond by virtue of $A$ ssumption 4 . This assumption ensures that $s^{L}$ increases at a faster rate than ${ }^{\circ}$; the rate at which $\mathrm{S}^{\mathrm{E}}$ increases. Alternatively, the 'reversed' admittance result also obtains with the restriction that the function $u$ belongs to the hyperbolic absolute risk aversion (HARA) family that satisfy DARA. Such functions imply that $s^{L}$ is convex in $d$ (Appendix I). If neither Assumption 4 nor DARA-HARA holds, $s^{L}$ may be concave in $d$ for any given $w$ : In this case it is no longer guaranteed that $S^{L}$ eventually exceeds the cost under the early oxer $\mathrm{s}^{\mathrm{E}}$ : A $\mathrm{s}$ a result, reversed admittance may not obtain, as there may not be a set of types with $w<w_{1}$ where an early oxer is the optimal choice of the club. Alternatively, the concave $s^{L}$ may intersect $s^{E}$ twice, generating either the reversed admittance pattern, or a pattern lateearly-late, depending on whether the second intersection lies above or below $\mathrm{d}^{\mathrm{NE}}$. Crucial and common to both sets of assumptions (Assumption 4 and DARA-HARA) is that $\mathrm{s}^{\mathrm{L}}$ increases by more than $\mathrm{s}^{\mathrm{E}}$ : This qualitative feature is most easily achieved by assuming absolute club enforcement power established by incurring a ..xed cost. In this case, the requirements for the reversed admittance result reduce to simple concavity of $u .^{10}$

\section{Commitment And The Viability Of Late Oxers}

In the framework of Section 3, there is but an endgame and potential commitment problems do not arise. For instance, if an applicant diverts all funds, the game ends before it has the opportunity to ask for more funding. Once two or more reform periods are considered, commitment axects the viability of the late oxer, while there is no room for opportunistic behavior in case of an early oxer. To analyze the role of commitment in the use of leverage for setting reform incentives, we focus on the subset of relatively poor applicants where the moral hazard problem is not dominated by the discount exect.

A ssumption 5 (Zero W ealth) All applicant types have zero wealth.

\footnotetext{
${ }^{10} \mathrm{~N}$ ote the importance of the concavity of $\mathrm{u}$ : $\mathrm{W}$ ith a linear felicity function, the marginal utility of consumption is a constant across states. Setting for illustration the marginal utility of consumption equal to one, the incentive constraint for reform under a late oxer is $\pm / 4+s=d+s$. Hence, the club cannot lessen the applicant's incentive to consume the reform funds by providing ex ante overfunding. In that case, $d^{\llcorner E}=\hat{d}$; and late entry is only dominant for $d \cdot \hat{d}:$
} 
While we restrict the analysis for simplicity to zero wealth applicants, the results results in this section apply qualitatively also to positive wealth levels below $\mathrm{w}_{1}:{ }^{11}$

On the one hand, late oxers are strictly dominant and $s^{L}=d$ if the club can fully commit not to renegotiate a stage-..nancing schedule. On the other hand, in a multi-period setting where the club cannot commit not to renew funding, the set of late oxer types gradually shrinks as the number of periods increases. The applicant can exploit this lack of commitment in two ways. Having received reform ..nance from the club, the applicant can deviate from the reform path by consuming the funds directly and returning next period for renewed funding. A Iternatively, it can spend all or part to lower its reform status in order to extract larger rents in coming periods because of its larger reform distance. We also show that the club will renege on its promise to reward an applicant for having fully reformed. This commitment problem prevents the club from implementing the late admittance strategy in the cheapest incentive compatible way.

\subsection{Stage-Financing}

In the previous section, the club was restricted to making a single payment in the beginning of the (reform) period. We now assume that the club can split both funding and reform requirement into slices and condition the transfer of any subsequent slice upon previous reform. The following two assumptions ensure that the club can make a credible threat to refuse future funding.

A ssumption 6 (Completion date) The club can commit to a completion date by which an applicant, holding a late oxer, must meet the club requirement in order to get admitted.

A ssumption 7 (Reform time) Changing the reform status by $\phi x$ requires time $\underline{L}(\phi x)$. For simplicity, $\underline{L}(\phi x)=\$ x$.

Under Assumptions 6 and 7, an applicant cannot count on an extension and hence, failure to reform at any stage renders full reform impossible. Thus, the club will not disburse further funds. Furthermore, given Assumption 7, the applicant cannot accelerate the reform process. Hence, it cannot compensate for times without reform investments by compressing more investments into an arbitrarily short period later. Since $\underline{\underline{L}}=d$, the minimum length of a full reform period dixers among applicant types, the more advanced being able to reach the club

\footnotetext{
${ }^{11}$ Due to Assumption $5(w=0)$, acceptance is weakly dominant for those types as the IC $-\mathrm{L}$ is slack.
} 
standard faster. Of course, an applicant may prolong the reform process by spending time without reforming. Denote by $L, \underline{L}$ the length of the whole reform period until an applicant $\mathrm{i}$, holding a late oxer, reaches the club standard and is admitted. Accordingly, the discount factor is $\pm=\mathrm{e}^{\mathrm{i}} \mathrm{rL}$; where $\mathrm{r}$ is the rate of time preference. First, we restrict attention to the class of stage...nancing oxers that implement full reform in the shortest time feasible $\underline{L}=d$ (fast reform schedule). Second, we prove that the fastest reform schedule is feasible and that it dominates all other schedules.

The club splits the reform period into A $2 \mathrm{~N}_{+}$stages. Each stage a 2 [1;A] lasts $\mathrm{I}^{\mathrm{a}}$ and is funded with $s^{a}$. The fast reform schedule without overfunding is given by $l^{a}=d^{a}, s^{a}=d^{a}$ if the applicant has invested $F^{a_{i}{ }^{1}}$ for $a>1$. (Obviously, $d^{1}$ is unconditional.)

Since e $e^{i} d_{1} / 4>u\left(d_{i}\right)$ for all $d<\hat{d}$ (Section 3), it follows that disbursing all the reform funds up-front is incentive compatible only for the most advanced applicants $(d \cdot \hat{d})$. All other candidates would divert funds if they were paid out up-front. Consider an applicant with a remaining distance \& to the club standard and discretion over an amount of money $\mathrm{m}$. The applicant invests $m$ in reforms if $\mathrm{e}^{\mathrm{i} \mathbb{t}_{1} / 4}, \mathrm{u}(\mathrm{m})$.

Lemma 4 The maximum incentive compatible reform funds are given by $m=u^{i}{ }^{3}$ ei $r \&_{1} / 4$ : The amount $m$ decreases with the remaining distance \&.

A shorter distance \&increases the opportunity costs of diverting the funds now, because the membership bene.ts accrue sooner. Hence, the incentive compatible amount of reform ..nance rises monotonically the closer the applicant's ongoing reform take it to the entry threshold. A closer 'carrot' 1/4exercises increased leverage on an impatient applicant. B ecause an applicant has to reform without any interruption under the fast reform schedule, Lemma 4 also determines the maximum interval between two consecutive disbursements of funds, and hence, a lower bound on the number of stages. Furthermore, continuous reform necessitates that the reform requirement equals the length of each stage, $I^{a}=d^{a}$. Recall that for the most advanced applicant types ( $d \cdot \hat{d})$, full reform without overfunding can be implemented using a single disbursement of $d_{i}$. That is, there is no need for stage-..nancing. For less advanced applicant types $d>\hat{d}$, splitting the disbursement of $d$ into stages eliminates the need to oxer rents. The inverse relationship between $\mathrm{m}$ and \& implies that the maximum interval between subsequent disbursements increases with the applicant's reform status. Hence, the maximum length of stage $a, \hat{d}^{a}$, is given by $\hat{d}=m \hat{d}=u^{i}{ }^{1} e^{\text {e } r \hat{d} / 4}$ : 
Lemma 5 For an applicant of type d, implementation of full reform without overfunding requires at least $\underline{A}$ stages where

$$
\mathbb{a}_{a=1}^{1} \hat{d}^{a}<d \cdot{ }_{a=1}^{X} \hat{d}^{a}:
$$

The stage length is chosen so small that the temptation to deviate reform funds at the stage is less than the cost of not joining the club. While the club can trivially construct any number of incentive compatible oxers without overfunding by splitting stages up further, no smaller number can be incentive compatible. A smaller number would imply larger reform and funding requirements per stage, violating the incentive constraint in at least one stage of the oxer. The initial reform status $x^{0}$ and the minimum number of stages are inversely related. In particular, if the club selects the maximum incentive compatible stage length for all following stages from the beginning, there is a scheme where the earliest stages are added to an otherwise unmodi..ed stage-..nancing scheme of a more advanced type.

Proposition 2 Under Assumptions 6 and 7, full reform can be implemented with no overfunding for all types. The optimal stage-..nancing schedule is the fast schedule with continuous funding $(A=1)$.

The Proposition follows by combining the results of Lemmas 4 and 5 and noting that the club always prefers increasing the number of stages because it delays disbursement of further funds. Since at each stage, a reform $d, \hat{d}>0$ is incentive compatible, Proposition 2 implies that within a ..nite minimum number of stages full reform is incentive compatible for any type without overfunding. Since the enlargement gains accrue only after reform, both the club and the applicant strictly prefer the fast schedule. ${ }^{12}$ Under the early oxer, the entrant retains rents $\frac{1_{i}{ }^{\circ}}{\circ} d>0$; and hence, early entry is strictly dominated.

Under Assumptions 6 and 7, stage-..nancing indeed reduces the cost of enlargement to the club to funding the pure reform expense. However, both assumptions are crucial for a successful stage-..nancing approach, and they are not in general satis..ed. First, the club must be able to commit not to re..nance (and grant an extension) at the end of the reform period. Second, it must not be possible for the applicant to 'accelerate' reforms, i.e., compressing full reform into one single stage. This assumption is needed to exclude opportunistic behavior that does

\footnotetext{
${ }^{12}$ The club can implement full reform without leaving the applicant rents using any stage-..nancing schedule with $\mathrm{L}>\mathrm{d}$ with a suф cient number of stages. Consider a schedule where the club grants the applicant reform time $L=\underline{L}+\phi:$ Trivially, full reform can still be implemented by allocating the entire delay $\pitchfork$ in an additional, pure delay stage of length $\phi$ and with $d^{1}=s^{1}=0$ at the start of the schedule. Having delays at some later time may require more than one additional stage.
} 
not require going beyond the end date. Without Assumption 7, re..nancing the full reform requirement at the beginning of the last stage would be optimal for the club. The anticipation of renewed ..nance in turn discourages reform of the applicant in all earlier stages. Hence, the viability of a stage-..nancing contract depends on the club's commitment power not to grant additional funding. The next Section analyzes the lack of commitment power of the club in a repeated game framework.

\subsection{Opportunism}

\section{[INCOMPLETE ]}

In the repeated game, the applicant can behave opportunistically in two ways. First, under a late oxer it can consume all funds it receives at the beginning of the period and return for renewed funding in the next period. In contrast to the one-period model, in all periods preceding the endgame, the club cannot credibly commit not to fund again. Second, the applicant can modify its starting position $\mathrm{x}^{0}$ strategically for a future enlargement situation. Since its rents rise in $d$, an applicant has an incentive to lower its position along dimension $\mathbf{x}$ in order to extract more money from the club with a renewed oxer. Either type of opportunistic behavior has the exect of shrinking the set of applicant types for which a late admittance oxer is used in early periods.

\subsubsection{Strategic Consumption}

As a simple illustration of the consequences of opportunistic behavior in the repeated game, consider ..rst a oncerepeated enlargement game of Section 2 under A ssumption 5 (zero wealth). The ..rst round covers dates 0 and 1 ; and the second dates 1 and $2 .{ }^{13}$ The optimal late oxer in the last period corresponds to the solution of the one-period model (Section 3). Hence, for $d>u^{i}{ }^{1}( \pm$ we have $\hat{s}$ from Lemma 1 as the optimal transfer. At date 0 ; the incentive constraint for reform is

$$
\pm / 4+u\left(s_{0}\right), u\left(s_{0}+d\right)+ \pm\left[ \pm / 4+u\left(s_{1}\right)\right]
$$

where equality de.nes $s_{0}{ }^{\prime} \hat{s}_{0}$ : Suppose $\hat{s_{0}}=\hat{s_{1}}$ ' $\hat{s}$. Substituting the de.nition of $\hat{s_{1}}$ $\pm 1 / 4+u(s)=u(s+d)$ yields $\left.0, \pm \pm 1 / 4+u\left(\hat{s}_{1}\right)\right]$ : Since $1 / 4>0$ and $\hat{s}_{1}=\hat{s}, 0$; this cannot be satis..ed for any $\pm>0$. Hence, so must exceed $\hat{s}_{1}$ :

\footnotetext{
${ }^{13} \mathrm{~N}$ otice the timing structure: Since no reform takes place between the realization of $\mathrm{x}$ at the end of the ..rst round and the issuing of an oxer in the beginning of the next round, both take place sequentially at date 1 :
} 
The incentive constraint for $\mathrm{T}=2$, equation (2), generalizes immediately to any $2<\mathrm{T}<1$ :

$$
\mathrm{u}\left(\mathrm{s}_{0}\right) \text { i } \mathrm{u}\left(\hat{\mathrm{s}}_{0}+\mathrm{d}\right)=\mathrm{i} \mathbb{\pm}_{4+}{ }_{\mathrm{t}=0}^{\mathrm{x}_{\mathrm{i}}{ }^{1}} \pm^{+1} \mathrm{u}\left(\mathrm{s}_{\mathrm{t}+1}+\mathrm{d}\right) \text { : }
$$

Lemma 6 In the $T<1$ times repeated enlargement game, the incentive compatible transfer with a late oxer strictly increases in $\mathrm{T}$ : Formally, 8t $2(0 ; \mathrm{T} ; 1) ; \hat{\mathrm{s}}_{\mathrm{t}}>\hat{\mathrm{s}}_{\mathrm{t}+1}$ : Furthermore, $\frac{d\left(\hat{s t i}_{\mathrm{i}} \hat{\mathrm{s}}_{\mathrm{t}}\right)}{\mathrm{dT}}<0$ :

The opportunity for the applicant to behave opportunistically in the beginning of the repeated game imposes a cost on the club that increases with the remaining length of the game. Thus, the cut-ox between late and early admittance oxers declines. Furthermore, the level $\hat{d}$ below which the late oxer does not leave any rents to an applicant falls and reaches zero within a ..nite number of periods.

For simplicity, the exect of discounting on overfunding is discussed with reference to $\mathrm{T}=2$ : From equation (2), it follows that

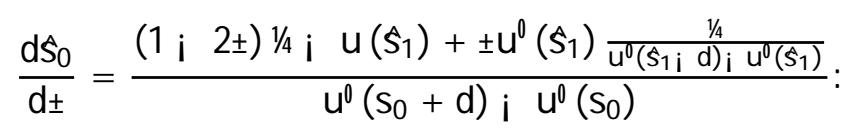

Expression (4) is of ambiguous sign. At high values of $\#$ the applicant is patient and tries to maximize the total consumption regardless of when it happens. With larger discounting current consumption is more valuable, while any delay is costlier. Equation (2) implies

$$
0,\left[u\left(s_{0}+d\right) ; u\left(s_{0}\right)\right]+\#\left(s_{1}\right) ;(1 ; \# \pm / 4
$$

The right-hand side consists of the opportunity cost of reforming in period 1; the second is the bene.t of waiting for next period's transfer, and the third the cost of delaying entry. The ..rst term weighs relatively most when $\pm=0$; the second when $\pm=1$; and the third when $\pm=\frac{1}{2}$ : For extreme values of \pm the incentive constraint cannot hold (unlike the one-shot enlargement game where any reform can be made incentive compatible via a suф ciently large overfunding). For intermediate values of $\#$ the transfer $S_{1}$ may rise or fall in \pm

In the beginning, the club has three enlargement strategies; that is $\mathrm{j}=\mathrm{L}$ in period 0 ; or in 1 ; and $\mathrm{j}=\mathrm{E}$ in period 0 : Clearly, a pro..table early oxer at date 0 strictly dominates one at date 1 for any $\pm<1$ : First, consider the choice of oxering late admission in period 0 versus 1 : The former is more pro..table if

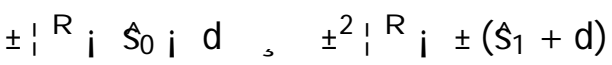

$$
\begin{aligned}
& \text { So . } \quad\left(1 \mathrm{i} \sharp^{\mathrm{i}} \#^{\mathrm{R}} \mathrm{i} \mathrm{d}^{\Phi}+ \pm \hat{s_{1}}\right. \text { : }
\end{aligned}
$$


The right-hand side is the sum of the cost to the club of delaying $(1 \mathrm{i} \#$ the enlargement gain net of the resource costs of actual reforms ${ }^{i} \#^{R}{ }_{i} d^{\Phi} ;$ and the present value of the future transfer. The club is the more inclined to pay for present entry the more costly delay is, and the more future entry will cost. As a result of the commitment problem making late oxers more expensive in the repeated game, substituting early admittance in the ..rst round for either late oxer is more attractive than in the one-shot game.

Corollary 3 The threshold between early and late oxers, $d_{t}^{L E}$; weakly decreases in the number of periods remaining. ${ }^{14}$

Consider now the in..nitely repeated enlargement game. The incentive constraint in any period $t$ is

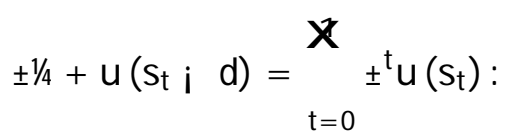

Only a constant value of $\mathrm{s}_{\mathrm{t}}=\mathrm{s}^{\mathrm{a}}$; 8t; can be a solution. A ny increasing or decreasing path would violate the players' budget constraints (..nite resources as constraint on club spending). Hence, in equilibrium we have

$$
\begin{aligned}
& \pm / 4+u\left(s^{\alpha} i d\right)=\prod_{t=0}^{X} \pm\left(s^{\circledR}\right) ; \\
& \pm / 4=\frac{u\left(s^{x}\right)}{1 i \pm} i u\left(s^{a} i d\right):
\end{aligned}
$$

This condition de..nes the minimum incentive compatible level of overfunding with in..nitely many periods remaining. ${ }^{15}$ Clearly, $\frac{\mathrm{ds}^{\mathbb{R}}}{\mathrm{d}^{1 / 4}}<0$ and $\frac{\mathrm{ds}^{\mathbb{1}}}{\mathrm{dd}}>0$ : We apply the implicit function theorem on (8) to obtain ${ }^{16}$

$$
\frac{d s^{a}}{d \pm}=i \frac{\left.u\left(s^{a} i d\right)+1 / 42 \pm i \quad 1\right)}{u^{0}\left(s^{a}\right) i\left(1 ; \quad \# u^{0}\left(s^{a} i d\right)\right.}
$$

This expression is of ambiguous sign. For \pm sul ciently close to 1 the derivative is negative, but for small \pm the denominator is negative and the numerator ambiguous. The ambiguity

\footnotetext{
${ }^{14}$ Corollary 3 is a weak rather than strict statement because the cutox $d_{t}^{L E}$ is truncated below by 0 .

${ }^{15}$ If the club membership bene..ts accrue in every period of membership rather than only once, the constraint is more easily satis..ed:

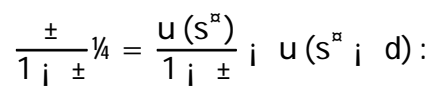

However, for all $d>\hat{d} ; s^{x}>0$; and hence, the commitment problem remains strictly costly for the club.

${ }^{16} \mathrm{~W}$ ith per-period bene.ts the expression takes a simpler form. After substituting for $1 / 4$ from the incentive

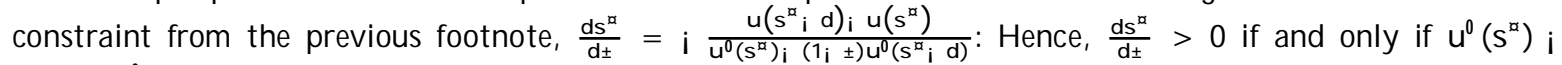
$\left(1 ; \# u^{0}\left(s^{\sharp} ; \quad d\right)>0\right.$ : Clearly this can only hold for suఢ̣ ciently large \pm
} 


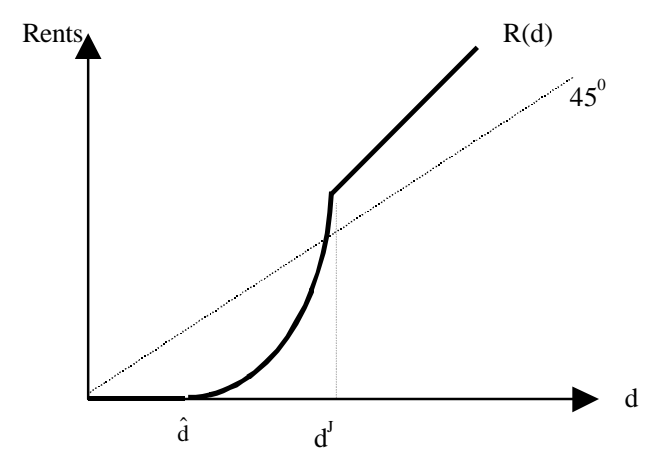

Figure 6: Strategic Deterioration

derives from the presence of two opposing exects that discounting has on the incentive to reform. On the one hand, impatience lowers the value of the consumption stream derived from not reforming $\left(\frac{\mathrm{u}\left(\mathrm{s}^{\mathrm{n}}+\mathrm{d}\right)}{1_{\mathrm{i}} \pm}\right.$ falls). On the other hand, impatience also means that the discounted membership gain, i.e., the incentive to reform, is valued less. The two exects are of changing relative strength because the former is non-linear $\left(\frac{\mathrm{u}\left(\mathrm{s}^{\mathrm{u}}+\mathrm{d}\right)}{\mathrm{l}_{\mathrm{i}} \pm}\right.$ becomes arbitrarily large as \pm rises) and the latter linear.

Hence, in the repeated game, the late admittance strategy becomes relatively less attractive, either because entry may be delayed (in the ..nitely repeated game), or because it involves larger rents for the applicant. ${ }^{17}$ T hus, the range of applicant types for which late entry is the cheaper strategy shrinks ( $d^{L E}$ decreases).

\subsubsection{Strategic Deterioration}

Consider again the once repeated enlargement game. Instead of consuming the reform funds, an appliant can use the funds to divest, i.e., deteriorate its starting position from $x^{0}$ to $x^{0} i F$. The incentive to do so stems from the fact that the rents to the applicant are increasing in $\mathrm{d}$ : This additional possibility to extract rents from the club aggravates the opportunistic behavior problem.

The gain from investing in strategic deterioration of $x$ is shown in Figure 6. For $d<\hat{d}$ the applicant retains no rents in the late conditional oxer, while for $\hat{d}<d<d$; it receives rents (Proposition 1). For $d<d<d^{N E}$; the rents are given by ${\frac{1 i^{\circ}}{\circ}}^{\circ} d$ under an early oxer. The cost of strategic deterioration is given by the $45^{\circ}$ line. The applicant engages in strategic

\footnotetext{
${ }^{17}$ Farell and Maskin (1989) show that renegotioation proof threats can be constructed in repeated prisoner's dilemma games. This threat involves zero rents for the punishing player. In our case, since the club can pro..tably employ the early entry oxer, this credible threat strategy with a late oxer is strictly dominated.
} 
deterioration if the gain $\mathrm{R}(\mathrm{d})$ net of the cost of deterioration yields a higher utility increase than the discounting cost of delaying membership.

If the applicant has an incentive to use reform ..nance to increase the reform distance, it is a strictly dominant strategy for the club to defer a late oxer. Hence, the club's action in the ..rst period is determined by a comparison between an early oxer now and a late oxer next period. This comparison yields a strictly lower level of $d$; the cut-ox level of reform distance above which the club makes an early oxer, and below which it makes a late oxer in the next period. Discounting lowers the club's payo from this deferred late oxer and hence, of is lower now.

If the number of future periods rises, the late oxer is deferred until the last period. Hence, it gets more discounted, and the threshold between a deferred late oxer, and an early one now, shifts down.

Corollary 4 If the applicant has an incentive to strategically deteriorate, as T ! $1 ; d_{t}^{L E}$ ! 0 and the only oxers made are early oxers. For $\mathrm{T}<1$; any late oxer is made in $\mathrm{T}$.

In conclusion, both types of opportunistic behavior raise the cost to the club of the late conditional oxer scheme. The longer the remaining time horizon, the lower the threshold between early and late admittance, and the lower the level $\hat{d}$ up to which the late oxer requires no rents to the applicant.

\subsubsection{Rewarding Entry}

A ssuming commitment, the stage-..nancing schedule reduces $S^{L}$ to $d$. The idea is to raise the gain from not deviating relative to the stepwise reduced cost for the applicant. The ratio of bene..t to cost of reforming can also be raised if the club requires full reform in one go, but raises the bene.t of entering. In particular, the club could raise the applicant's reform incentives by oxering a reward conditional on entry. Oxering a pure reward $p$ to any successful entrant, the gain to reforming and entering is $\mathbb{t}_{4}+\#$ (p) while the opportunity cost is $u(d)$ : Hence, a suф ciently high p can induce any applicant type to reform fully.

However, as in the previous section, this strategy again relies on the assumption of exogenous commitment. Since reform is not veri..able, the applicant is not guaranteed entry even if it reforms. Since it cannot insist on admittance, its outside option ex post is worth zero, which is less than accepting entry without payment of $\mathrm{p}$ and at least receive $1 / 4$ (In fact, if the applicant 
were not ..nancially constrained, the club could even extract part or all of $1 / 4$ as well). Hence, any prize oxered for entry is not renegotiation-proof. ${ }^{18}$

Note the crucial role of the non-veri..ability of the reform status $\mathrm{x}$ : If $\mathrm{x}$ was contractible, not only would a pure reward scheme become a viable alternative to the pure overfunding scheme, but the club could even use both to construct an even more cost-ec cient way to induce full reform. The option of rewarding entry would clearly be a non-trivial addition to the contracting space, since a comparison of the incentive constraints for the pure overfunding $( \pm / 4+\#(s), u(s+d))$ and the pure reward scheme $( \pm / 4+\#(p), u(d))$ shows that the pure reward is strictly cheaper for \pm suф ciently close to 1: Furthermore, since both overfunding and the reward accrue in dimerent periods, concavity of $u$ ( $\phi$ implies that a mixed contract would be strictly superior to either pure one. ${ }^{19}$

\subsection{Sources of Commitment Power}

\section{[PRELIMINARY ]}

The power of future membership as incentive mechanism depends on the credibility of the club's threat to refuse additional funding. In the preceding section, we show that with strong commitment ability, the club can use stage ..nancing to reduce the transfer to poor applicants to the pure reform cost. In this case, the late oxer is strictly dominant. In contrast, lacking any commitment power in the repeated game leads to opportunistic behavior that renders the late oxer unpro..table. ${ }^{20}$ Here, we discuss brieły two modi..cations of the basic model that create exogenous commitment. (In Section 4.1 commitment came from Assumptions 7 and 6.) Both mechanisms we discuss rely on competition among a pool of applicants.

First, the current membership size may be such that inclusion of all current applicants, even if reformed, would exceed a limit on pro..table enlargements. R easons for such a saturation membership level may be convex crowding costs that on the critical margin exceed $廿_{+}^{R}$ :

\footnotetext{
${ }^{18} \mathrm{G}$ oing back to the applicants that dixer in both $\mathrm{d}$ and $\mathrm{w}$; there is a further way in which commitment problems prevent the club from making best use of the late oxer. In the one-period model of Section 3, applicants with large wealth relative to reform distance had to pay an 'admittance fee' to the club. In the repeated game, the club, instead of admitting the reformed applicant, can take the fee and make a new take-it-or-leave-it oxer next time, demanding additional payment. This problem is easily overcome by taking the entrance fee only upon actual entry. Both the payment and actual entry are observable and veri..able, so this contract would not pose problems.

${ }^{19} \mathrm{~W}$ ith $\mathrm{x}$ veri.. able, the entrant's share $1 / 40$ of the total (gross) enlargement surplus ${ }^{\mathrm{R}}+1 / 4$ can be interpreted as rełecting relative bargaining power. We have so far assumed that $1 / 4$ is either non-veri..able or non-transferable, and that the club has all bargaining power. An alternative formulation would be to let $1 / 4+\left.\right|^{R}$ be transferable and give the applicant such bargaining power that it can extract a share $\frac{1 / 4}{R^{1 / 4}}$ of $1 / 4+I^{R}$ in ex post negotiations. This alternative setup results in the same incentive structure as before.

${ }^{20} \mathrm{Credible}$ threats in repeated prisoner's dilemma games have been analyzed (Farrell and M askin, 1989).
} 
The club pre.nances at least one more applicants than it could take in. While it is still an equilibrium for all applicants not to reform, there is now another equilibrium where all reform and enter if there are suф ciently many oxers. The expectation that other candidates reform makes reform strictly optimal for any single potential deviant. Alternatively, the club may have limited resources. Spending all available funds on pre...nancing current applicants creates a credible last opportunity for them to reform and pursue the enlargement gain $1 / 4$ Interestingly, the club makes all enlargement oxers simultaneously, thus making its resource constraint strictly binding. Bunched entry results as solution to the commitment problem.

\section{Conclusion}

We analyze the strategic use of the club membership and reform ..nance decisions to induce an applicant to reform. The main result lies in a 'reversed' admittance order. A dvanced applicant types enter after having reformed, while less advanced types enter early and have their reforms monitored by the club. All but the most advanced entrants obtain rents that increase with their reform distance. We also show that the use of future membership bene.ts as an incentive mechanism ceases to be exective when the club cannot commit to deny refunding in the future. Crucial for the reversed admittance result is an assumption on the curvature of the applicant's utility function that lets the cost of the moral hazard problem under a late oxer increase faster in reform distance than the club's internal monitoring cost. We have discussed alternative formalizations that are equivalent in creating a tradeox between the leverage of a late oxer and the monitoring capability of an early oxer; if no such assumption is satis..ed, the late oxer may be a dominant strategy for any applicant type.

The analysis can be extended in a variety of directions. The club standard may change over time, or be a choice variable of the club. Information asymmetries between an applicant and the club concerning the initial reform level or the cost of reforming (or equivalently, the productivity of any given investment) creates an adverse selection problem. Furthermore, the club may have the option to invest of its own, axecting the payox matrix of the game. In the EU enlargement situation, this version of the model could provide insights into the 'widening' versus 'deepening' debate, i.e., whether internal EU reform should precede enlargement or not. Finally, and again motivated by the EU example, heterogeneity of incumbent club members plays a crucial role in forming the enlargement strategy. 


\section{APPENDIX}

\section{A Proof of Lemma 1 (R eform Implementation)}

Part (i): Once admitted, an applicant has no incentives to reform. Hence, ${ }^{\circ}{ }^{i} s^{E}+w^{\Phi}, d$ must hold for full reform to be feasible, giving a minimum transfer of $\mathrm{s}^{\mathrm{E}}=\frac{\mathrm{d}}{\mathrm{o}} \mathrm{i}$ w:

Part (ii): Provided an applicant has accepted a late oxer, the club minimizes s subject to

$$
w+s, d
$$

and

$$
\pm 1 / 4+u(w+s i d), \underset{a}{u}(w+s):
$$

For types $(d ; w): d<u^{i}{ }^{1}\left( \pm / A\right.$ and $w 2(0 ; 1)^{2}$; the IC-L is slack, given that reform is feasible. Hence the minimum incentive compatible transfer is $s^{L}=d_{i} \quad w$ :

For types $(d ; w): d>u^{i}{ }^{1}\left( \pm / 4\right.$ and $w 2(0 ; 1), s=d_{i}$ w violates the IC $-L$. Thus, the minimum incentive compatible transfer is such that $\pm / 4+u(w+s i d)=u(w+s)$. Finally,

$$
\frac{d \hat{s}}{d \pm}=i \frac{1 / 4}{u^{0}(w+s i d) ; u^{0}(w+s)}<0 \text { and } \frac{d \hat{d}}{d \pm}=\frac{\frac{1}{3} / 4}{u^{0} \hat{d}}>0 \text { : }
$$

\section{B Proof of Lemma 2 (A cceptance Early)}

The club minimizes s subject to

$$
w+s, \frac{d}{o}
$$

and

$$
1 / 4+u(w+s i d), u(w)
$$

Feasibility of reform requires that $w+s, \frac{d}{\sigma}$ (Lemma 1), and the new entrant retains $w+s_{i} d, \frac{1}{0}_{0}^{\circ} d$ after reforming. Thus, the IR $-E$ requires $1 / 4+u(w+s i d), 1 / 4+u \frac{1_{i} \circ}{\circ} d$, $u(w)$ : Hence, for $w<u^{i} 1 \frac{1 / 4+u}{i_{i}^{\circ}} d$ (Region I), the FC-E binds and $S^{E}=\frac{d}{\circ} i \quad w$ : In Region II, the IR -E binds and $S^{E}=d_{i} w+u^{i}{ }^{1}[u(w) ; 1 / 4$ :

Derivation of ${ }^{i} L R^{E}$ i $F C^{E}$ : Substituting $w+s=\frac{d}{o}$ from the FC-E into the IR-E directly yields $1 / 4+u \frac{1_{i}{ }^{\circ}}{o} d=u(w)$ as the equation de..ning the ${ }^{i} I R^{E} i F^{E}$ curve. This curve is concave. Total dimerentiation yields

$$
\frac{d d}{d w}=\frac{\circ}{1 i^{\circ}} \frac{u^{0}(w)}{u^{0} \frac{1_{i}^{\circ}}{\circ} d}>0 ;
$$

and hence,

$$
\frac{d^{2} d}{d w^{2}}=\frac{\circ}{1 i^{\circ}} \frac{u^{\boxplus}(w)}{u^{0} \frac{1_{i}^{\circ}}{\circ} d}<0
$$




\section{Proof of Lemma 3 (Acceptance Late)}

The club minimizes s subject to

$$
\begin{aligned}
& \pm 1 / 4+u(w+s ; d), u(w+s) ; \\
& \pm / 4+u(w+s ; d), u(w) ;
\end{aligned}
$$

and

$$
w+s, d:
$$

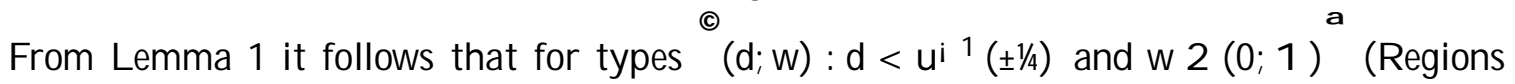
$I I I$ and IV), the IC - L is always slack. By the same reasoning, the IR $-L$ is slack for $w<u^{i}{ }^{1}( \pm / 4$ (Region III), and $S^{L}$ is determined by the FC-L. Conversely, for $w, u^{i}( \pm / A$ (Region IV) the IR-L determines $S^{L}$ :

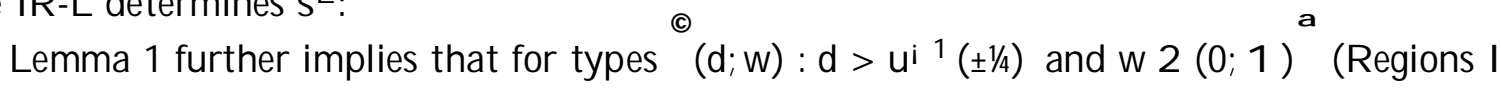
and II), the IR-L binds for $S$. 0 (Region II) and the IC $L$ binds for $S>0$ (Region I), while the FC-L is al ways slack. Solving the $I C-L$ (or $I R-L$ ) for $S=0$ yields the ${ }^{i} I R^{L} ; I C C^{L}$ curve, $d=w_{i} u^{i}{ }^{1}\left[u(w) ; \pm A\right.$ : Being the $I C-L$ for $s=0$; the ${ }^{i} I R^{L}{ }_{i} I C^{L}{ }^{\Phi}$ is concave in $w$. Totally dixerentiating the IC $-L$ for $S, 0$ yields

$$
\begin{aligned}
\frac{d d}{d w} & =\frac{u^{0}(w+s i d) i u^{0}(w+s)}{u^{0}(w+s i d)} \\
& =1 i \frac{u^{0}(w+s)}{u^{0}(w+s i d)} 2(0 ; 1)
\end{aligned}
$$

and

$$
\frac{d^{2} d}{d w^{2}}=\frac{i u^{\oplus}(w+s) u^{0}(w+s i d)+u^{0}(w+s) u^{\oplus}(w+s i d)}{u^{0}(w+s i d)^{2}}
$$

Hence, $\frac{d^{2} d}{d w^{2}}<0$ if and only if $i u^{\oplus}(w+s) u^{0}(w+s i d)<i u^{0}(w+s) u^{\oplus}(w+s i d)$; which amounts to assuming DARA.

\section{Proof of Proposition 1}

We ..rst compare the cost to the club of making an early and a late oxer of admittance for any type, and then analyze the choice between making an oxer and making no oxer.

Lemmas 2 and 3 together divide the space of applicant types into ..ve regions (Figure 7). The club chooses between an early and a late oxer by comparing for each region the respective transfers.

Lemma 7 (Regions 1 and 2) For all types with $w$, $u^{i}{ }^{1}\left(1 / 4\right.$ and $d \cdot u^{i}\left[u(w) i^{1 / 4} \frac{\circ}{1_{i}{ }^{\circ}}\right.$, $s^{E} \cdot s^{L}$ : 


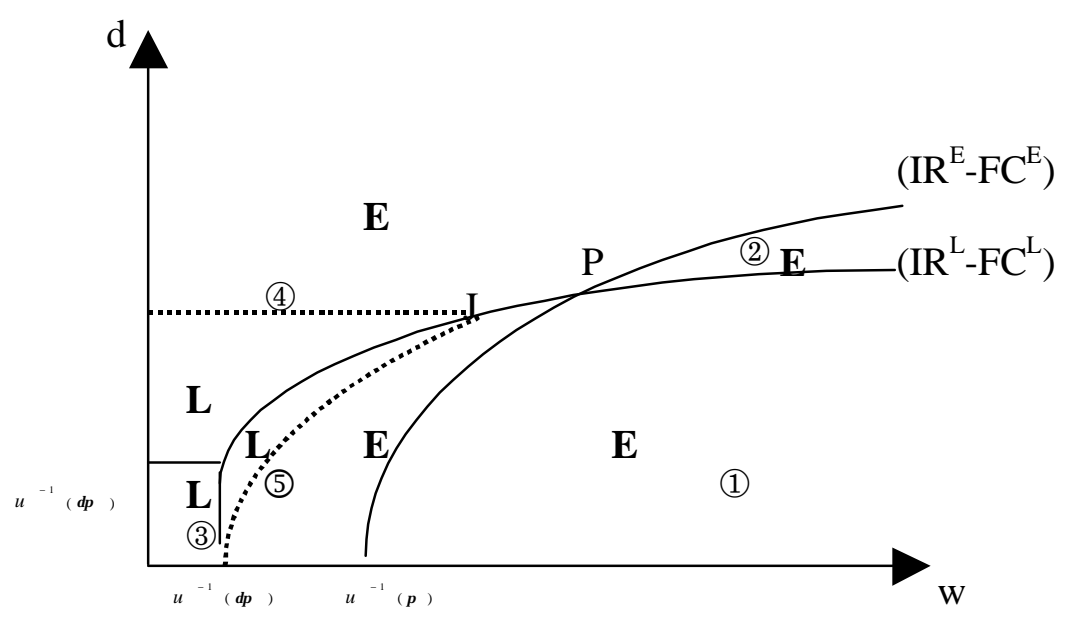

Figure 7: Early Versus Late Oxers

Proof. For the above types, $s^{E}=d_{i} w+u^{i}{ }^{1}\left[u(w) ;{ }^{1 / 4}\right.$ from Lemma 2 , while $s^{L}$ is either equal to $d_{i} w+u^{i}{ }^{1}\left[u(w) ; \pm^{ \pm} / 4\right.$ (Region 1$)$ or implicitly de. ned by $s=d_{i} w+u^{i}{ }^{1}\left[u(w+s) i \pm^{2} / 4>0\right.$ (Region 2) from Lemma 3. Since $s^{L}>0$ in Region 2 and $\pm / 4<1 / 4$ the early oxer is more pro..table in either case.

For all types $w<u^{i} 1_{1 / 4}^{h}+u^{3} \frac{l_{i} \circ}{\circ} d d^{\prime}$; the IR-E is slack. Hence, in the remaining part of the proof we only need to compare the FC-E with the transfer under the late oxer.

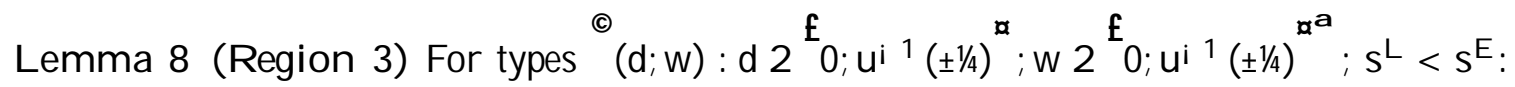

Proof. By Lemmas 2 and $3, s^{L}=d_{i} w<\frac{d}{\circ} ; w=s^{E}$; which follows from ${ }^{\circ} 2(0 ; 1)$ :

Lemma 9 (Region 4) For types with $d>u^{i}{ }^{1}\left( \pm / f\right.$ for $w<u^{i}{ }^{1}\left( \pm / A\right.$ and typep $d, w_{i j}$ $u^{i}{ }^{1}\left[u(w)\right.$ i $\pm_{4}^{1}$ for $w, u^{i}{ }^{1}\left( \pm A\right.$, there exists a unique ${ }^{2}$ de. ned by $\pm_{4} / 4=u \quad \frac{d}{\sigma}$ i u $\left(1 ;{ }^{\circ}\right) \frac{d}{\sigma}$ such that for $d<d^{*}, s^{L}<s^{E}$; and $s^{L}, s^{E}$ for $d, \sigma$. Moreover, $\varangle<d^{N E}$.

Proof. For these types, $s^{L}$ as de.ned by $s=d i w+u^{i}{ }^{1}[u(w+s) i \pm 4$ is compared to $\frac{d}{\circ} i w=s^{E}$ : Setting $s^{L}=s^{E}$ yields the de..nition of $\alpha_{h}^{L}$ Late admittance is cheaper if

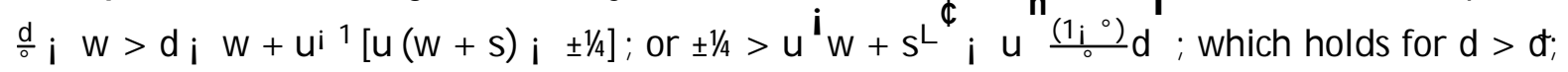
while early is (weakly) cheaper otherwise.

3 Existepce and upiqueness of $₫$ and $\varangle<d^{N E}$ all follow from Assumption 4. The dixerence

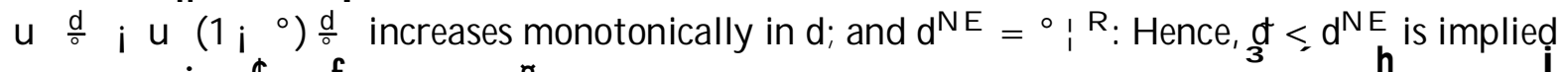

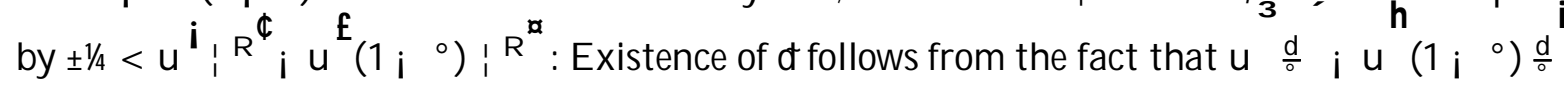
equals zero for $d=0$; that this dixerence increasesmmonotonjically, and that $\varangle<d^{N E}$. Finally, uniqueness follows directly from monotonicity of $u \frac{d}{o} i \quad u\left(1 ;{ }^{\circ}\right) \frac{d}{o}$ in $d$ : 


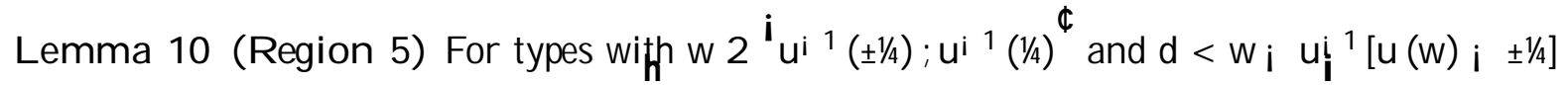

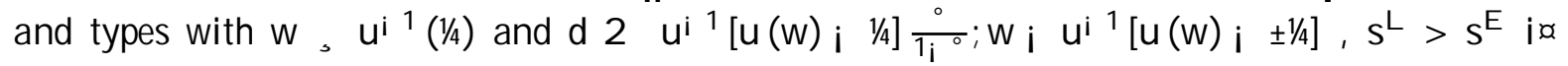
$d<u^{i}{ }^{1}\left[u(w) i \pm / 4 \frac{\circ}{1 i^{\circ}}\right.$; and $s^{L} \cdot s^{E}$ otherwise.

Proof. For these types, the club compares $s^{E}=\frac{d}{o} ; \quad w$ and $d i w+u^{i}{ }^{1}\left[u(w) i \quad \pm / 4=s^{L}\right.$ : Hence, $s^{E}<s^{L}$ if $\frac{d}{\circ}$ i $w<d i w+u^{i}{ }^{1}\left[u(w)\right.$ i $\frac{+}{c} / 4$ : Rearranging yields $d<u^{i}{ }^{1}\left[u(w)\right.$ i $\pm 4 \frac{0}{l_{i}{ }^{\circ}}$ : Equating $s^{E}$ and $s^{L}$ de.nes the ${ }^{i} F C^{E} i \quad R^{L}{ }^{C}$ curve, $d=u^{i}{ }^{1}\left[u(w) i \pm \frac{\circ}{1_{i}{ }^{\circ}}\right.$. This curve is concave. Total dixerentiation yields

$$
\frac{d d}{d w}=\frac{u^{0}(w)}{u^{0} \frac{1_{i}^{\circ} \circ}{0^{\circ}} d} \frac{\circ}{1 i^{\circ}}>0 \text { and } \frac{d^{2} d}{d w^{2}}=\frac{u^{\infty}(w)}{u^{0}{\frac{1 i^{\circ}}{\circ}}^{\circ} d} \frac{\circ}{1 i^{\circ}}<0 \text { : }
$$

Lemma 11 (Point J) The ${ }^{\mathrm{i}} F C^{E}{ }_{i} I R^{L^{\Phi}}$ and ${ }^{i} \frac{1}{3} R^{L} i, l C^{L}{ }_{3}^{\$}$ Curves have a unique intersection (Point J); with $d$ implicitly de. ned by $\pm / 4+u \quad \frac{1_{i}{ }^{\circ}}{\circ} d=u$ d . Moreover, $d>u^{i}( \pm / 4$ :

Proof. $T$ he ${ }^{i} F C^{E} ; I R^{L}{ }^{\Phi}$ curve is de. ned by $s^{E}=s^{L}$; while on ${ }^{i} I R^{L} ; I C^{L^{\phi}}$ the transfer $s^{\mathrm{L}}=0$ : Hence, at any intersection $\mathrm{s}^{\mathrm{E}}=\mathrm{s}^{\mathrm{L}}=0$ must hold, and this point also must lie on $d={ }^{\circ} \mathrm{W}$ (the iso-transfer ${ }_{3}$ line with $s_{3}{ }_{3}=, 0$ ). Substituting $w=\frac{d}{\sigma}$ into ${ }^{i} F^{E} C_{i} I R^{L^{\Phi}}$ (or

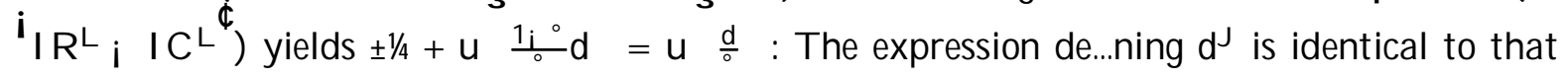
de..ning $d$. Thus, existence, uniqueness, and $d<<d^{N E}$ all follow from Lemma 9. Moreover,

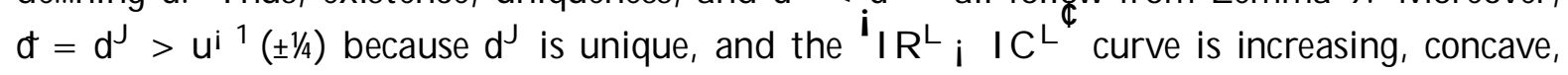
and passes above ${ }^{\circ} \mathrm{W}$ at $\mathrm{w}=\mathrm{u}^{\mathrm{i}}{ }^{1}( \pm / \mathrm{A}$.

Note that the curve $\left(F C^{E} i_{3} R^{L}\right)$ as given by $\pm^{2} / 4+u \frac{1_{i}}{\circ} d=u(w)$ is everywhere above the curve $\left(R^{E}{ }_{i} F^{E}\right), 1 / 4+u \frac{1_{i}}{\circ} d=u(w)$; and has the same slope. Hence, the latter intersects the ${ }^{i} I R^{L}{ }_{i} I C^{L}{ }^{\Phi}$ (Point $P$ ) to the right of Point $J$ : This completes the comparison of an early and a late oxer.

Although full reform is feasible under either enlargement strategy, the cost of providing the applicant with suф cient acceptance and reform incentives may exceed the bene.t of reformed enlargement to the club.

Lemma 12 (No Oxer) Under Assumption 4, a pro.table late admittance oxer implies a pro..table early oxer, but the reverse does not hold.

Proof. The inequality $d^{N E}>d^{N L}$ requires $\pm^{2} / 4<u^{i} \#^{R}+w^{\phi} i u^{f}\left(1 ; \quad{ }^{\circ}\right)^{i} \#^{R}+w_{\phi}^{\phi \alpha}$ : Part (i) of Assumption 4 implies that for $w=0 ; d^{N E}>d^{N L}$ : By Part (ii), $u^{i} \#^{R}+w^{4} i$ $u^{ \pm}\left(1 i^{\circ}\right)^{i} \#^{R}+w^{Q Q}$ increases monotonically in $w$. Hence, the $d^{N L}$ curve lies everywhere below the $\mathrm{d}^{\mathrm{N} E}$ curve.

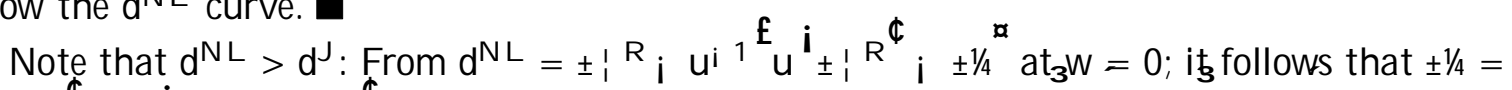
$u^{i}{ }_{\Psi}{ }^{\Phi}{ }_{i} u^{i}{ }_{\sharp}{ }^{R} d^{N L} L^{\Phi}$ : Equating this expression with $\pm / 4=u \quad \frac{d}{0}$ i $u \frac{1_{i}^{\circ}}{0} d$ (de. nition 


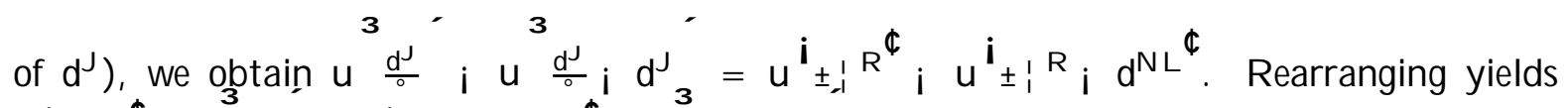

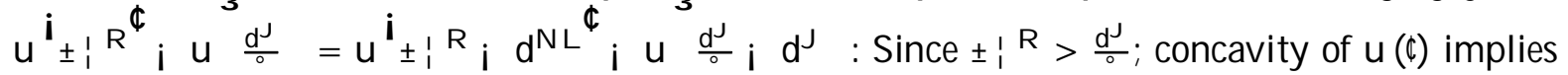
that this can only hold if $d^{l}<d^{N L}$ :

\section{E Proof Of Corollary 1}

Recall $w_{1}{ }^{\prime} u^{i^{1}( \pm / A} ; w_{2}: \pm / 4+u\left[\left(1 i^{\circ}\right) w\right]=u(w) ;$ and de..ne $w_{3}{ }^{\prime}{\frac{1}{\circ}{ }^{\circ}}^{\circ} d$ : We ..rst give a formal restatement of Corollary 1 . The optimal transfer is

(i) $s$ ऋ $d$ for all types:

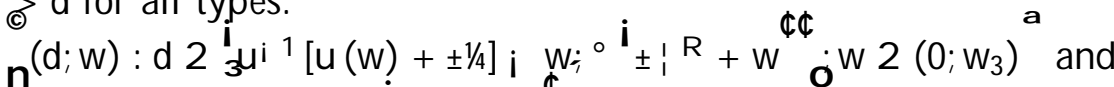

$$
\begin{aligned}
& (\mathrm{d} ; \mathrm{w}): \mathrm{d} 2 \quad \frac{\mathrm{i}_{\mathrm{o}}^{\circ}}{\circ} \mathrm{w} ;{ }^{\circ}{ }^{\mathrm{i}} \mathrm{H}^{\mathrm{R}}+\mathrm{w}^{\Phi} ; \mathrm{w} 2\left(\mathrm{w}_{3} ; 1\right) \text { (Region I); }
\end{aligned}
$$

(ii) $0<\mathrm{C}<\mathrm{d}$ for all types:

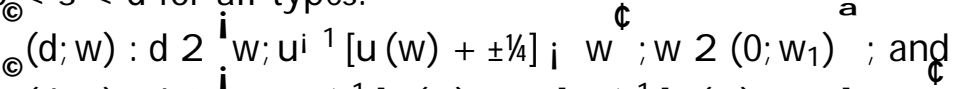

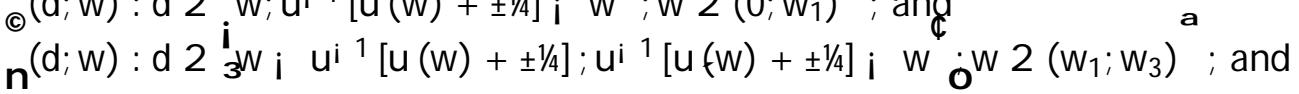

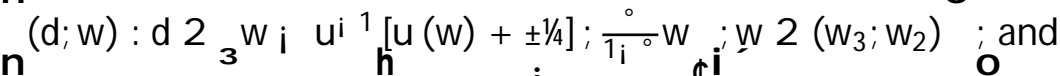

$$
\begin{aligned}
& (\mathrm{d} ; \mathrm{w}): \mathrm{d} 2{ }^{\circ} \mathrm{w} ; \min \frac{\circ}{\mathrm{l}_{\mathrm{i}}^{\circ} \mathrm{w}}{ }^{\circ}{ }^{\mathrm{i}} \mathrm{H}^{\mathrm{R}}+\mathrm{w}^{\mathrm{C}} ; \mathrm{w} 2\left(\mathrm{w}_{2} ; 1\right) \text { (R egion II); }
\end{aligned}
$$

(iii) $\mathrm{s} \cdot 0$ for all types:

$$
\begin{aligned}
& f_{d}(d ; w): d 2(0 ; w) ; w 2\left(0 ; w_{1}\right) g ; \text { and } \\
& (d ; w): d 2^{1} 0 ; w_{i} u^{i}{ }^{1}\left[u(w)+ \pm 4^{4} ; w_{2} 2\left(w_{1} ; w_{2}\right)^{\underline{a}}\right. \text {; and } \\
& \mathrm{f}(\mathrm{d} ; \mathrm{w}): \mathrm{d} 2\left(0 ;{ }^{\circ} \mathrm{w}\right) ; \mathrm{w} 2\left(\mathrm{w}_{2} ; 1\right) \mathrm{g} \text { (Region III). }
\end{aligned}
$$

Proof. The $s=d$ line: For $d>d>u^{i}{ }^{1}( \pm / 4$; the IC $-L$ binds. Substituting $s=d$ in the IC $-L$ yields $d=d_{i} w+u^{i}\left[u(w+d) ; \pm / 4\right.$; which simpli..es to $d=u^{i}{ }^{1}[u(w)+ \pm / 4 ;$ w with $\frac{d d}{d w}=\frac{u^{0}(w)_{i} u^{0}(w+d)}{u^{0}(w+d)}>0$ : DARA then implies concavity. For $d, d ; s^{E}=\frac{d}{\sigma} ;$ w: Subştituting

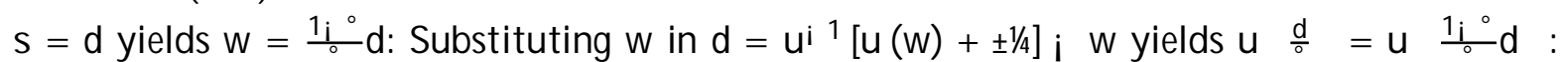
Hence, the two curves meet on the horizontal $d$ line. The corresponding $w$ coordinate follows from $w=\frac{1_{i}^{\circ}}{\circ} d d^{\prime} w_{3}$.

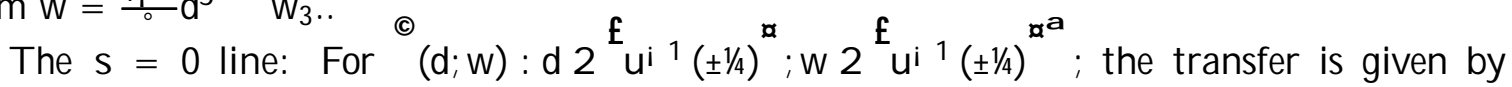
$s^{L}=d_{i}$ w: Hence, the $s=0$ line has $d=w$ : For $w 2\left(w_{1} ; w_{2}\right)$ the $s=0$ line is given by ${ }^{\mathrm{i}} \mathrm{I} \mathrm{R}^{\mathrm{L}} \mathrm{i} I \mathrm{C}^{\mathrm{L}}{ }^{\Phi}$ : For $\mathrm{w}>\mathrm{w}_{2}$; the transfer is $\mathrm{s}^{\mathrm{E}}=\frac{\mathrm{d}}{\mathrm{o}} \mathrm{i} \mathrm{w}$; and hence, the $\mathrm{s}=0$ line is $\mathrm{d}={ }^{\circ} \mathrm{w}$.

\section{F P roof Of Corollary 2}

The no-oxer separating line is $d^{N E}=0^{i} \#^{R}+w^{\Phi}$ with $\frac{d d^{N E}}{d^{\circ}}>0$ and $\frac{d d^{N E}}{d \pm}>0$. From $\frac{1}{3}$ emma 11 , the upper separating line between late and early oxer, $d$; is de.ned by $\pm / 4=u \quad \frac{d}{0} \quad$ i

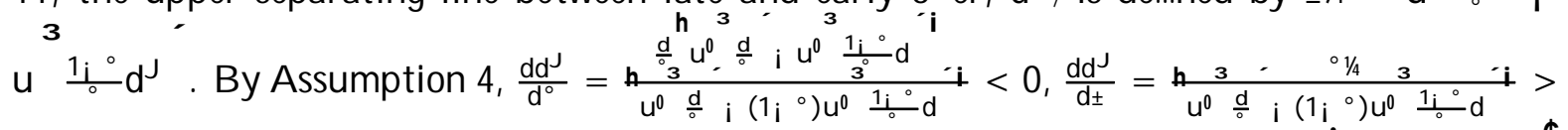

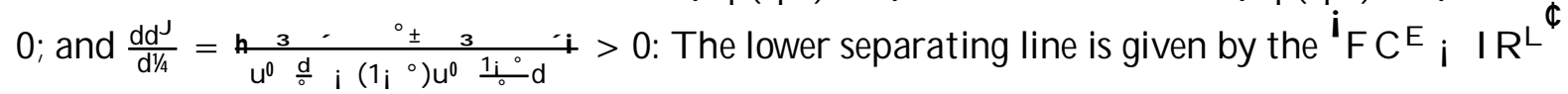


curve, $d=u^{i}{ }^{1}\left[u(w)\right.$ i $\pm / 4 \frac{\circ}{1_{i}{ }^{\circ}}$ : It follows immediately that $\frac{d d}{d^{\circ}}=u^{i}{ }^{1}\left[u(w)\right.$ i $\pm / 4 \frac{1}{\left(1_{i}{ }^{\circ}\right)^{2}}>0$;

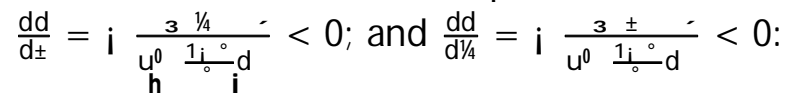

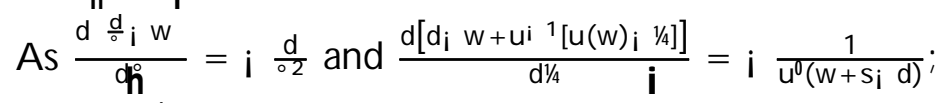

$\mathrm{S}^{\mathrm{E}}=\max \frac{\mathrm{d}}{\mathrm{a}} \mathbf{i} \mathbf{w} ; \mathrm{d}_{\mathrm{i}} \mathbf{w}+\mathrm{u}^{\mathrm{i}}\left[\mathrm{u}(\mathrm{w}) \mathrm{i}^{1 / 4}\right.$ weakly decreases in ${ }^{\circ}$ and $1 / 4$

$$
\text { As } \frac{d\left(d_{i} w+u^{i}{ }^{1}[u(w) i \pm \pm / 4)\right.}{d \pm}=i \frac{1 / 4}{u^{0}(w+s i d)} ; \frac{d\left(d_{i} w+u^{i}{ }^{1}[u(w) i \pm 1 / 4)\right.}{d^{1 / 4}}=i \frac{ \pm}{u^{0}(w+s i d)} ;
$$

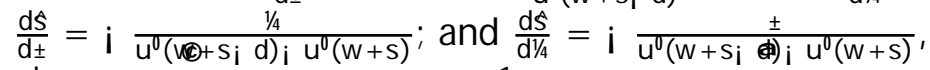

$\mathrm{s}^{\mathrm{L}}=\max \mathrm{d}_{\mathrm{i}} \mathrm{w} ; \mathrm{d}_{\mathrm{i}} \mathrm{w}+\mathrm{u}^{1}\left[\mathrm{u}(\mathrm{w}) \mathrm{i} \pm \frac{\mathrm{A}}{4} ; \hat{\mathrm{s}}\right.$ also weakly decreases in \pm and $1 / 4$

\section{G Proof of Lemma 6}

The Lemma follows from (3) by noting that by concavity of $u ;\left[u\left(s_{0}\right) ; u\left(s_{0}+d\right)\right]$ increases in $\mathrm{s}_{0}$ : Concavity of $\mathrm{u}\left(\mathrm{S}_{\mathrm{t}+1}\right)$ also implies that successive increments in $\mathrm{s}_{0}$ get smaller as $\mathrm{T}$ rises.

\section{H Admittance Oxers W ithout R eform}

In this section we analyze the club's optimal behavior for non-reform implementing oxers. First, we show that no oxer strictly dominates a late, non-reform implementing oxer. Second, we derive the optimal non-reform implementing early oxer and identify the set of types that accept such an oxer. Third, we show that A ssumption 3 implies that the club strictly prefers no oxer to a non-reform implementing early oxer.

Lemma 13 ( N ever N o-R eform Late) Making no oxer strictly dominates an accepted, nonreform implementing late oxer.

Without reform, the club never admits a late applicant as $\mathrm{U}<0$ : Hence, an applicant accepts a non-reform implementing late oxer if and only if $s, 0$; since then $u(w+s)>u(w)$. Since ${ }^{U}$ i $s<0$; the club strictly prefers making no oxer.

Lemma 14 (Early No Reform) Applicant types with $w_{h} u^{i}{ }^{1}{ }_{3}^{1 / 4}+u, \frac{1_{i}}{0^{\circ}} d ~ ' i$ an early, non-reform implementing oxer. For $w<u^{i} 1 \frac{1 / 4+}{u} \frac{1_{i}{ }^{\circ}}{d}$; the optimal nonreform implementing early oxer has a transfer

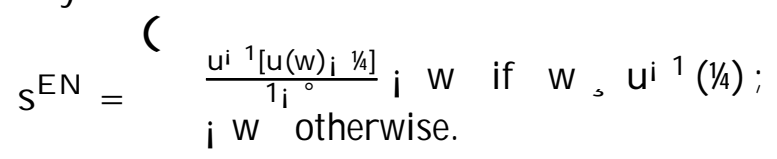

Proof. The condition for an early oxer that leaves insul cient funds for reform is 0 . ${ }^{\circ}(w+s)<d$ : T he applicant rejects such an oxer if and only if $1 / 4+u\left[\left(1 i^{\circ}\right)(w+s)\right]<u(w)$ :

For $w<u^{i} 1 / 4+u \frac{1_{i}{ }^{\circ}}{o} d$, the club minimizes s subject to

$$
1 / 4+u\left[\left(1 ;{ }^{\circ}\right)(w+s)\right], u(w)
$$

and 


$$
\frac{d}{o}>w+s, 0
$$

If $\mathrm{u}(\mathrm{w})<1 / 4$ then the club can extract all the applicant's wealth, i.e., $\mathrm{s}=\mathrm{i}$ w: Otherwise, the IR -EN binds.

We now compare admittance without reform with no oxer.

Lemma 15 ( N ever N o-R eform Early) Given A ssumption 3, making no oxer strictly dominates an accepted, non-reform implementing early oxer.

Proof. Lemma 14 implies that the club's payox from a non-reform implementing oxer is at most $i^{U}+u^{i} 1(1 / 4:$

W hile simple, the condition in Assumption 3 is overly strong, since it would be suф cient that no reform is dominated by either no oxer or reformed entry.

\section{The Curvature of $\mathrm{s}^{\mathrm{L}}$}

In general, the curvature of the transfer $s^{L}$ in $d$ is ambiguous. Let ${ }^{0}+{ }^{0}$ denote the argument $w+s$ in $u$; and no subscript $w+s$ i $d$ : Dixerentiation of $\frac{d s}{d d}$ from Footnote 5 yields

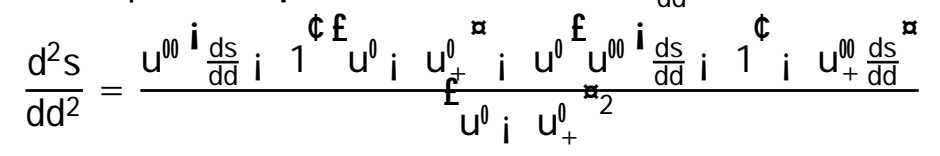

Substituting for $\frac{d s}{d d}$ and simplifying, the numerator can be written as $u^{\mathbb{Q}} u_{+}^{\infty} i \quad u_{+}^{\Phi} u^{\infty}$. Hence, $\frac{d^{2} s}{d d^{2}}>0$; i.e., $s^{L}$ is convex in $d$, if and only if

$$
\mathrm{i} \frac{\mathrm{u}^{\infty}}{\mathrm{u}^{\Phi}}>\mathrm{i} \frac{\mathrm{u}_{+}^{\infty}}{\mathrm{u}_{+}^{(\mathbb{Q}}}
$$

This condition holds for a diminishing coec cient of absolute risk aversion, weighted by

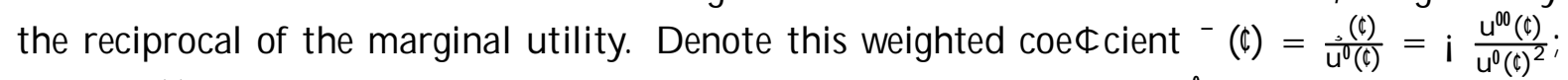
where,$\left(\phi\right.$ is the standard coec cient of absolute risk aversion. While ${ }^{-0}<0$ does not hold for (negative) exponential or logarithmic utility functions, it holds for instance for $u\left(\phi=p_{\bar{\phi}}\right.$

We can show that ${ }^{-0}<0$ is generally satis..ed for a subset of DARA-HARA functions. Following Merton (1971), hyperbolic absolute risk aversion (HARA) functions can be written as

$$
\mathrm{U}(\mathrm{x})=\frac{1 \mathrm{i} \circ \mu}{\circ} \frac{-\mathrm{x}}{1 \mathrm{i}^{\circ}}+{ }^{\prime \text { ी }} \circ \text {; }
$$

with $^{-}>0 ;{ }^{\circ} \boxminus 1 ;{\frac{-}{1} \mathrm{i}^{\circ}}^{\circ}+{ }^{\prime}>0$ and ${ }^{\prime}=1$ if ${ }^{\circ}=\mathrm{i} 1:$ The coec cient of absolute risk aversion of this class of functions is

$$
A(x)=\frac{1}{\frac{x}{1 i^{\circ}}+-}
$$

which leads to

$$
A^{0}(x)=\frac{3^{i} 1}{\left(1 i^{\circ}\right) \frac{x}{1_{i}^{\circ}+y^{\prime}}}
$$


Hence, $A^{0}(x)<0$ for ${ }^{\circ}<<_{3} 1$; which, de. nes a subset DARA-HुARA of the general HARA functions. With $U^{0}(x)=-\frac{-x}{1 i^{\circ}}+{ }^{,}{ }^{\circ}{ }^{1}$ and $U^{\oplus}(x)=i^{-2} \frac{-x}{1_{i}{ }^{\circ}}+{ }^{\circ}{ }^{\circ} 2$; the weighted coet cient of absolute risk aversion of HARA functions is then

$$
\mathrm{i} \frac{\mathrm{U}^{\oplus}}{\mathrm{U}^{\Phi}}=\frac{\mu-\mathrm{x}}{1_{\mathrm{i}}^{\circ}}+{ }^{\prime}{ }^{\mathfrak{7}_{\mathrm{i}}} \text { : }
$$

We have diminishing (weighted) absolute risk aversion if and only if

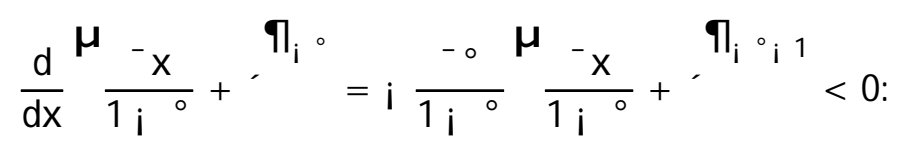

Hence, a necessary and suф cient condition for this condition to hold is ${ }^{\circ} 2(0 ; 1)$ under the restriction to real-valued utility. This de. nes the subclass of DARA-HARA functions for which the weighted measure of absolute risk aversion is decreasing.

\section{J Proof of Lemma 4}

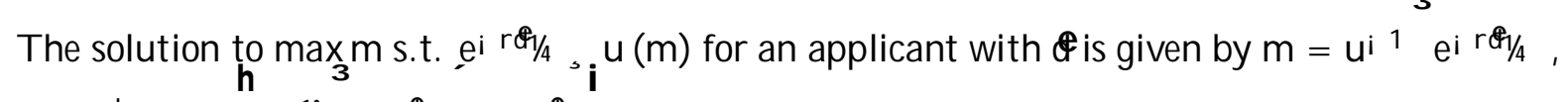
with $\frac{d m}{d \notin}=$ i ui 10 ei $r \mathbb{1}_{1} / 4$ rei $r \mathbb{H}_{1} / 4<0$.

\section{K Proof of Lemma 5}

No overfunding implies $\varsigma_{P}^{a}=d^{a}$ for $a=1 ; \ldots ; \underline{A}$. Feasibility of full reform requires ${ }_{A}^{P}{ }_{a=1} d^{a}, d_{i}$. Thus, for $\mathrm{p}^{\text {all }} \mathrm{A}_{\mathrm{i}}<\underline{A},{ }_{a=1}^{A} \hat{d}^{a}{ }_{P} d_{i}$ and either full reform is not feasible or at least one $d^{a}>u^{i}{ }^{1} e^{i d \hat{d} / 4}$. For $A>\underline{A}, \quad{ }_{a=1}^{A} \hat{d}^{a}>d_{i}$ and an incentive compatible schedule with at least one stage less exists. 


\section{References}

[1] Baldwin, Richard, Francois, J oseph and Portes, Richard, 1997. The Costs and B ene.ts of Eastern Enlargement: The Impact on the EU and Central Europe, Economic Policy 24, 127-76

[2] Berglöf, Erik and Gerard Roland, 1998, The EU as an 'Outside Anchor' for Transition R eforms. SITE W orking Paper No. 132, Stockholm School of Economics

[3] Bolton, Patrick and Scharfstein, David, 1990. A Theory of Predation Based on Agency Problems in Financial Contracting, American E conomic Review, 80, 93-106.

[4] Buchanan, J ames, 1965. An Economic Theory of Clubs, E conomica 32, 1-14

[5] Cornes, Richard, and Sandler, Todd, 1996. The Theory of Externalities, Public Goods, and Club Goods. 2nd Edition, Cambridge University Press; Cambridge, New York and Melbourne.

[6] Diamond, D. 1991. Monitoring and Reputation: The Choice Between Bank Loans and Directly Placed Debt, J ournal of Political E conomy 99: 689-721.

[7] Farrell, J oseph, and Eric Maskin, 1989. Renegotiation in Repeated Games, Games and E conomic Behavior 1, 327-360

[8] Gromb, Denis, 1994. Renegotiation in Debt Contracts, mimeo.

[9] Hart, Oliver and Moore, J ohn, 1994. A Theory of Debt Based on the Inalienability of Human Capital, Quarterly J ournal of E conomics 109: 841-79

[10] Holmström, Bengt and Tirole, J ean, 1997. Financial Intermediation, Loanable Funds, and the Real Sector, Quarterly J ournal of E conomics 112 (3), 663-692

[11] Merton, R.C, 1971. Optimum Consumption and Portfolio Rules in a Continuous-Time Model, J ournal of E conomic Theory 3: 373-413

[12] Sandler, Todd and T schirhart, J ohn T., 1980. The Economic Theory of Clubs: An Evaluative Survey, J ournal of E conomic Literature 18(4), 1481-1521

[13] T iebout, Charles, 1956. The Pure Theory of Local Expenditures, J ournal of Political E conomy 64, 416-24

[14] T irole, J ean, 1988. The Theory of Industrial Organization, M IT Press, Cambridge, M A

[15] Williamson, Oliver, 1975. Markets and Hierarchies: A nalysis and A ntitrust Implications, Free Press, New York 